\title{
Spillovers between food and energy prices and structural breaks
}

\author{
Alanoud Al-Maadid ${ }^{\mathrm{b}}$, Guglielmo Maria Caporale ${ }^{\mathrm{a}, *}$, Fabio Spagnolo $^{\mathrm{a}}$, \\ Nicola Spagnolo ${ }^{\mathrm{a}}$

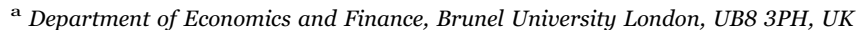 \\ b College of Business and Economics, Qatar University, Qatar
}

\section{A R T I C L E I N F O}

\section{JEL classification:}

C32

F36

G15

\section{Keywords:}

Energy and food prices

VAR-GARCH BEKK model

Mean and volatility spillovers

\begin{abstract}
A B S T R A C T
This paper estimates a bivariate VAR-GARCH $(1,1)$ model to examine linkages between food and energy prices. The adopted framework is suitable to analyse both mean and volatility spillovers, and also allows for possible parameter shifts resulting from four recent events, namely: (1) the 2006 food crisis, (2) the Brent oil bubble, (3) the introduction of the Renewable Fuel Standard (RFS) policy, and (4) the 2008 global financial crisis. The empirical findings suggest that there are significant linkages between food and both oil and ethanol prices. Further, the four events considered had mixed effects, the 2006 food crisis and 2008 financial crisis leading to the most significant shifts in the (volatility) spillovers between the price series considered.
\end{abstract}

\section{Introduction}

The relationship between energy and food prices has been analysed extensively in the literature. Their behaviour in terms of trends and volatilities appears to be rather similar. The recent crisis in the period 2006-2008 substantially affected these prices (e.g., wheat prices increased from $\$ 3.8$ to $\$ 8.8$ per bushel and corn prices from $\$ 2.6$ to $\$ 7$ ). This sharp increase is a serious concern for the developing economies. According to the World Bank report (De Hoyos and Medvedev, 2011), the impact of the recent crisis on global welfare was to push between 75 and 160 million people into poverty. Furthermore, food-importing countries were exposed to political instability and internal conflicts. The higher price volatility has also generated additional uncertainty and had adverse effects on investment.

The links between energy and agricultural commodity prices were first analysed by Barnard (1983). The three-fold increase in the demand for bio-fuel in recent years has led to the introduction in the US in 2005 of the so-called Renewable Fuel Standard (RFS) policy. This policy aims to reduce pollution by requiring vehicles to use methyl tertiary butyl ether (MTBE) an oxygenate, as gasoline to improve combustion and reduce harmful vehicle emissions. The RFS policy is in effect in New York and Connecticut, states that had previously accounted for a total of $42 \%$ of national MTBE consumption. It was approved in 2005 but was not enforced until June 2006. This new standard required motor fuels to contain a minimum amount of fuel coming from renewable sources, such as biomass (e.g., ethanol), solar power or wind energy. Since then, ethanol has been the only practical way to comply with the new standard. Therefore, in mid-2006, ethanol became the only available gasoline additive (Avalos, 2014). Abbott et al. (2009) described the link between food and fuel and argued that these two markets were historically independent until 2006, when ethanol usage became large enough to influence world energy prices. From 2006, the RFS policy started having an impact on ethanol price as much as on oil and gasoline, in addition to other factors such as supply and demand, macroeconomic variables, and exchange rates.

\footnotetext{
* Corresponding author.

E-mail address: Guglielmo-Maria.Caporale@brunel.ac.uk (G.M. Caporale).
} 
The higher demand for ethanol oil as a bio-fuel alternative to natural oil has led to more land being used for its production. The 'food versus fuel claim' posits that an increased demand for bio-fuel production may result in less land allocated to food production, which can lead to higher food prices. Bio-fuel production increased three-fold in the period 2006-2012. de Gorter et al. (2013) argued that food prices increased owing to RFS policies in rich countries only.

Most studies rely on standard supply and demand or equilibrium frameworks to model both fuel and food prices (e.g., Serra, 2011). These models have been criticised for not being sufficiently supported by empirical data and are plagued by poor performance (Hertel and Beckman, 2011; Serra and Zilberman, 2013); in addition, equilibrium models mainly employ annual data, which is a clear limitation. For instance, Timilsina et al. (2011) developed a multi-country, multi-sector general equilibrium model and used recursive techniques to simulate various oil price scenarios and assess the corresponding impact on bio-fuels production, agricultural output, land-use change and global food supply. One of the scenarios considered higher oil prices leading to an increase in bio-fuel price and a decrease in food supply. The effects of exchange rates have also been examined by other authors, such as who estimated an error correction model for cereal, food and non-food consumer prices using monthly data and found that agriculture and food have a dominant role in Ethiopia's economy. Baquedano and Liefert (2014) also used a (single equation) errorcorrection model to test for long-run relationships and price transmission from macroeconomic factors to consumer prices for wheat, rice, maize, and sorghum in the main urban centres of a selected number of countries in Asia, Latin America, the Caribbean, and Sub-Saharan Africa. Their results confirm that open economies are more vulnerable to international shocks. Hochman et al. (2014) adopted a multi-region framework dividing the world into regions, where demand for corn, rapeseed, rice, soybean, and wheat is shown to consist of demand food/feed, inventory, and (where applicable) bio-fuels. His results indicate that up to 25\% of the price of corn is driven by bio-fuel prices and up to $7 \%$ of the price of soybean by energy prices. He also examined the impact of shocks during periods when there are large inventories of food.

Very few papers examine the volatility of energy and agricultural prices. For instance, estimated volatilities to investigate the impact of bio-fuels on food and fuel prices up to 2013. McPhail and Babcock (2012) showed that ethanol, RFS and the blend wall lead to more inelastic demand for both corn and gasoline, which makes both markets more susceptible to supply shocks and leads to greater price volatility. They also estimated supply and demand elasticities for the US corn, ethanol, and gasoline markets using a three-stage least squares approach to provide empirical evidence for their theoretical set-up. Further, they developed a stochastic partial equilibrium model that explicitly accounts for important sources of volatility in the corn-ethanol-gasoline links, including stochastic corn yields and crude oil prices. Argued that only $8 \%$ of the increase in corn prices during the 2006-2009 period was the result of ethanol subsidies. They attributed the remainder to market forces and other factors, such as droughts, floods, a severe US recession, and two general commodity price surges. Ethanol policies, such as RFS, mandates and blend wall regulations, can affect the price variability of both corn and gasoline. Qiu et al. (2012) used a structural vector auto-regression (SVAR) model to show how supply/demand structural shocks affect food and fuel markets. Their results support the hypothesis that increased bio-fuel production causes short-run food price increases but not long-run price shifts. However, agricultural products, such as corn, are affected by their own trade shocks. Their findings also suggest complementarity between ethanol and gasoline and the idea that demand and supply market forces are the main drivers of food price volatility.

The study of volatility can benefit from high frequency data both because high-frequency volatility is easier to predict and because it has proven useful to forecast over longer horizons (Andersen et al., 2003). The most popular view is that the grain price boom from 2006 was the result of many factors, with bio-fuels being just one of them, and that bio-fuel policies account for only a fraction of the effects of bio-fuels. The food crisis caused the price of wheat, corn and soybeans to double between 2006 and mid-2008. Volatility issues and macro-policies aimed at achieving more stable food and oil prices have become increasingly important (Wright, 2011). Surveys of the literature investigating the economic impact of bio-fuels have paid particular attention to structural models. Zhang et al. (2009), using weekly data, examined price volatility interactions between the US energy and food markets in the period 1989-2007 by estimating the BEKK model of Engle and Kroner (1995). Their results suggest that there is no relationship between fuel (ethanol, oil and gasoline) prices and agricultural commodity (corn and soybean) prices. However, they did not control for the 2006 food crisis and the 2005 RFS policy.

Headey (2011) argued that previous research has generally relied on a specification of the variance-covariance matrix that does not allow for asymmetric impacts of price increases and decreases on volatility. They found that the high volatility persistence of commodity prices may be due to failing to account for structural breaks. Serra et al. (2011) also used a standard BEKK model to analyse volatility interactions between crude oil, ethanol and sugarcane prices in Brazil using weekly prices during the 2000-2008 period. In a related study on the same topic Serra (2011) used semi-parametric MGARCH models. Both papers suggest that there is a relationship between sugar and energy prices. Wu et al. (2011) estimated a restricted asymmetric MGARCH model using US corn and oil prices from 1992 to 2009 to investigate volatility spillovers between oil and corn prices. They concluded that corn markets have become much more connected to crude oil markets after the implementation of the RFS policy of 2005. Du et al. (2011) used futures market prices for crude oil, corn and wheat from 1998 to early 2009 to estimate stochastic volatility in their returns. The correlation coefficient between crude oil and corn markets was found to increase from 0.07 to 0.34 after October 2009, while that between crude oil and wheat markets increased from 0.09 to 0.27 , indicating a much tighter linkage between crude oil and agriculture commodity markets in the second period. Trujillo-Barrera et al. (2012) estimated a similar model using futures prices for crude oil, ethanol and corn from 2006 to 2011, and identified volatility spillovers from the crude oil futures market to the ethanol and corn futures markets.

Employed a univariate GARCH model and impulse responses to examine volatility transmission between world oil and selected world agricultural commodity prices (wheat, corn, soybeans, and sugar). They considered two sub-periods, before and after the food crisis, $01 / 01 /$ 1986-31/12/2005 and 01/01/2006-21/03/2011. Their causality-in-variance tests suggest that there is no transmission between oil and the agricultural commodity markets in the pre-crisis period, and no oil market volatility spillovers to the agricultural markets (with the exception of sugar during the post-crisis period). 
Gardebroek and Hernandez (2013) examined oil, ethanol and corn prices in the US between 1997 and 2011 and used a multivariate GARCH approach to estimate interdependence and volatility spillovers between these markets. Their results indicate higher interaction between ethanol and corn markets in recent years and particularly after 2006, when ethanol became the sole alternative oxygenate for gasoline. However, they observed significant volatility spillovers only from corn to ethanol prices but not the reverse. Also, they did not find sizeable volatility spillovers from the oil to the corn markets. In another study using the univariate GARCH $(1,1)$ and EGARCH models, Wang and Zhang (2014) examined price volatility interactions between China's energy and bulk commodity markets between 2001 and 2010. They split the sample before and after 2007 and found that there is greater volatility clustering between the food and oil markets after the 2007 oil shock.

Olsen et al. (2014) used a univariate GARCH model for food prices only. They found evidence of different structural breaks for energy and food commodities (such as grains) respectively. The latter are more volatile than other commodity prices (for metals) and display bidirectional (linear and non-linear) linkages to stock price indices. These findings suggest an impact on aggregate price indices not only of shocks to commodity demand and supply, but also of non-commodity shocks, as embodied in aggregate price indices, both linearly and nonlinearly. Chen et al. (2014) identified in the crude oil market a structural break in July 2004. Showed that grain prices have increased significantly since 2006 owing to several factors. Jebabli et al. (2014) focused on the recent financial crisis and its effects on volatility spillovers between food and energy prices. Fan and Xu (2011) stressed that the recent bubble in oil prices (2004-2008) and the resulting structural break should also be considered.

Mensi et al. (2014) examined the impact of three types of OPEC news announcements on the volatility spillover and persistence in the spot prices of oil and a set of agriculture commodity prices using a multivariate GARCH. OPEC announcements were found to exert influence on oil markets.

Han et al. (2015) used a multivariate normal mixture model and daily futures data from January 2000 to January 2014 to capture the structural properties of energy and three food commodities (corn, soybeans and wheat). They identified five breaks: (1) investment into commodity factors in 2004, (2) the food crisis (3), the RFS policy act of 2005, (4) the financial crisis, (5) the introduction of new European Union rules for bio-fuels in October 2012. Their results indicate that it was the financial crisis that had the most significant impact on the food-energy nexus.

None of the papers mentioned above conducted proper tests for and determined the dates of possible structural breaks in the energy-food spot prices volatility spillovers. The present study aims to fill this gap by examining the impact of well-known recent events on spillovers between food and energy prices in both the first (mean) and second (volatility) moments in the context of a VARGARCH model with a BEKK representation. ${ }^{1}$ The layout of the paper is as follows. Section 2 outlines the econometric model. Section 3 describes the data and discusses the empirical results. Section 4 summarises the main findings and offers some concluding remarks.

\section{The econometric model}

We model the joint process governing energy prices (oil and ethanol) and food prices (cacao, coffee, corn, soybeans, sugar and wheat) using a bi-variate VAR-GARCH(1,1) framework. ${ }^{2}$ The model has the following specification:

$$
\mathbf{x}_{t}=\boldsymbol{\alpha}+\boldsymbol{\beta} \mathbf{x}_{t-1}+\gamma y_{t-1}+e_{t}
$$

where $\mathbf{x}_{t}=\left(\right.$ Energy $_{t}$, Food $\left._{t}\right)$.

The parameter vectors of the mean equation (1) are the constant $\boldsymbol{\alpha}=\left(\alpha_{1}, \alpha_{2}\right)$ and the autoregressive term $\boldsymbol{\beta}=\left(\beta_{11}, \beta_{12}+\beta_{12}^{*}+\beta_{12}^{* *}+\beta_{12}^{* * *}+\beta_{12}^{* * * *} \mid \beta_{21}+\beta_{21}^{*}+\beta_{21}^{* *}+\beta_{21}^{* * *}+\beta_{21}^{* * * *}, \beta_{22}\right){ }^{3}$ To control for the business cycle $($ Campbell, 1999) we include the S \& P 100 index $\left(y_{t}\right)$ in the mean equation (this effect is measured by the parameters $\gamma=\left(\gamma_{1} \mid \gamma_{2}\right)$. To account for the possible effects of the recent crisis, we include four dummy variables: the first (denoted by ${ }^{*}$ ) captures the 2006 food crisis (Nazlioglu et al., 2013); the second (denoted by **), captures the oil crisis during the March 19/03/2004-06/06/2008 period; the third (denoted by ***) controls for the RFS policy implementation in June 2006, as suggested by Avalos (2014) finally the fourth (denoted by $* * * *$ ) corresponds to the 2008 global financial crisis (originating on 15/09/2008, i.e. on the day of the collapse of Lehman Brothers), as suggested by Jebabli et al. (2014).

The residual vector $\mathbf{e}_{t}=\left(e_{1, t}, e_{2, t}\right)$ is bi-variate, $\mathbf{e}_{t} \mid I_{t-1} \sim\left(\mathbf{0}, H_{t}\right)$, with its corresponding conditional variance covariance matrix given by:

$$
H_{t}=C_{0}^{\prime} C_{0}+A_{11}^{\prime}\left[\begin{array}{ll}
e_{1, t-1}^{2} & e_{2, t-1} e_{1, t-1} \\
e_{1, t-1} e_{2, t-1} & e_{2, t-1}^{2}
\end{array}\right] A_{11}+G_{11}^{\prime} H_{t-1} G_{11}
$$

The parameter matrices for the variance equation (2) are defined as $C_{0}$, which is restricted to be upper triangular, and two unrestricted matrices $A_{11}$ and $G_{11}$. Therefore, the second moment will take the following form ${ }^{4}$ :

\footnotetext{
1 Caporin and McAleer (2012) showed that BEKK models should be preferred to DCC models when working with high-frequency data.

2 The model is based on the GARCH(1,1)-BEKK representation proposed by Engle and Kroner (1995).

${ }^{3}$ Note that the dummy variables are used to model shifts in the cross-parameters only, not in the autoregressive terms.

${ }^{4}$ The parameter $\left(a_{21}\right)$ in Eq. (3) measures the causality effect of variable 2 on variable 1 , whereas $\left(a_{21}+a_{21}^{*}\right),\left(a_{21}+a_{21}^{* *}\right),\left(a_{21}+a_{21}^{* *}\right)$ and $\left(a_{21}+a_{21}^{* * * *}\right)$ measure the possible effect of the 2006 food crisis, the 2004-2008 oil bubble accumulation period, the mid-2006 RFS policy change, and the 2008 financial crisis, respectively.
} 


$$
\begin{aligned}
& A_{11}=\left[\begin{array}{ll}
a_{11} & a_{12}+a_{12}^{*}+a_{12}^{* *}+a_{12}^{* * * *}+a_{12}^{* * * *} \\
a_{21}+a_{21}^{*}+a_{21}^{* *}+a_{21}^{* * *}+a_{21}^{* * * *} & a_{22}
\end{array}\right] \\
& G_{11}=\left[\begin{array}{ll}
g_{11} & g_{12}+g_{12}^{*}+g_{12}^{* *}+g_{12}^{* * * *}+g_{12}^{* * * *} \\
g_{21}+g_{21}^{*}+g_{21}^{* *}+g_{21}^{* * *}+g_{21}^{* * * *} & g_{22}
\end{array}\right]
\end{aligned}
$$

Eq. (2) models the dynamic process of $H_{t}$ as a linear function of its own past values, $H_{t-1}$, and past values of the squared innovations $\left(e_{1, t-1}^{2}, e_{2, t-1}^{2}\right)$. The BEKK model guarantees by its construction that the covariance matrix in the system is positive definite. Given a sample of $T$ observations, a vector of unknown parameters $\theta$ and a $2 \times 1$ vector of variables $\mathbf{x}_{t}$, the conditional density function for model (1) is:

$$
f\left(\mathbf{x}_{t} \mid I_{t-1} ; \theta\right)=(2 \pi)^{-1}\left|H_{t}\right|^{-1 / 2} \exp \left(-\frac{\mathbf{u}_{t}^{\prime}\left(H_{t}^{-1}\right) \mathbf{u}_{t}}{2}\right)
$$

The log-likelihood function is:

$$
L=\sum_{t=1}^{T} \log f\left(\mathbf{x}_{t} \mid I_{t-1} ; \theta\right)
$$

where $\theta$ is the vector of unknown parameters. The standard errors are calculated using the quasi-maximum likelihood methods, which is robust to the distribution of the underlying residuals.

\section{Empirical analysis}

\subsection{Data}

We use daily data, from Bloomberg, for two energy spot prices (crude oil and ethanol) and six food commodity prices (cacao, coffee, corn, soybeans, sugar and wheat) over the period 1/1/2003-6/6//2015, for a total of 2253 observations. Furthermore, we use the S \& P500 stock market index as a proxy for the US business cycle (Campbell, 1999). We define daily returns as the logarithmic differences of the energy and food price indices.

Figs. 1 and 2 show food and energy commodity spot prices and returns respectively. The descriptive statistics presented in Table 1 concern the two sub-periods before and after the 2006 food crisis. Post-crisis volatilities are significantly higher for oil, coffee and corn. The increased volatility and larger extreme events (measured by maximum and minimum values) observed in the second sample affect, as one would expect, the Jarque-Bera statistics which indicate larger departures from normality in the post-crisis compared to the pre-crisis sample. ${ }^{5}$ The sample pairwise correlations with food commodities, reported in Table 2 , are generally positive for oil and negative for ethanol. There is evidence of correlation between food and energy price returns before the food crisis, significant and positive correlation between oil and cacao, coffee, corn, soybeans, sugar and wheat, and negative correlations between ethanol and cacao, and sugar in the post-crisis period.

\subsection{Hypotheses tested}

We test for mean and volatility spillovers, by placing restrictions on the relevant parameters; specifically, we consider the following four sets of null hypotheses:

1. Tests of no spillovers from food to energy prices:

$H_{0} 1 \mathrm{a}:$ Food $\rightarrow$ energy: $\beta_{12}=0$.

$H_{0} 1 \mathrm{~b}:$ Food $\rightarrow$ energy after the first breakpoint: $\beta_{12}^{*}=0$.

$H_{0} 1 \mathrm{c}:$ Food $\rightarrow$ energy after the second breakpoint: $\beta_{12}^{* *}=0$.

$H_{0} 1 \mathrm{~d}:$ Food $\rightarrow$ energy after the third breakpoint: $\beta_{12}^{* * *}$.

$H_{0} 1 \mathrm{e}:$ Food $\rightarrow$ energy after the fourth breakpoint: $\beta_{12}^{* * * *}=0$.

2. Tests of no volatility spillovers from food to energy prices:

$H_{0} 2 \mathrm{a}:$ Food $\rightarrow$ energy: $a_{21}=g_{21}=0$.

$H_{0} 2 \mathrm{~b}:$ Food $\rightarrow$ energy after the first breakpoint: $a_{21}^{*}=g_{21}^{*}=0$.

$H_{0} 2 \mathrm{c}:$ Food $\rightarrow$ energy after the second breakpoint: $a_{21}^{* *}=g_{21}^{* *}=0$.

$H_{0} 2 \mathrm{~d}:$ Food $\rightarrow$ energy after the third breakpoint: $a_{21}^{* *}=g_{21}^{* * *}=0$.

$H_{0} 2 \mathrm{e}:$ Food $\rightarrow$ energy after the fourth breakpoint: $a_{21}^{* * * *}=g_{21}^{* * *}=0$.

3. Tests of no spillovers from energy to food prices:

$H_{0} 3 \mathrm{a}:$ Energy $\rightarrow$ food: $\beta_{21}=0$.

\footnotetext{
${ }^{5}$ Descriptive statistics for the remaining three breaks are available on request. They show a similar pattern, with higher energy and food price volatilities in the second subsample.
} 

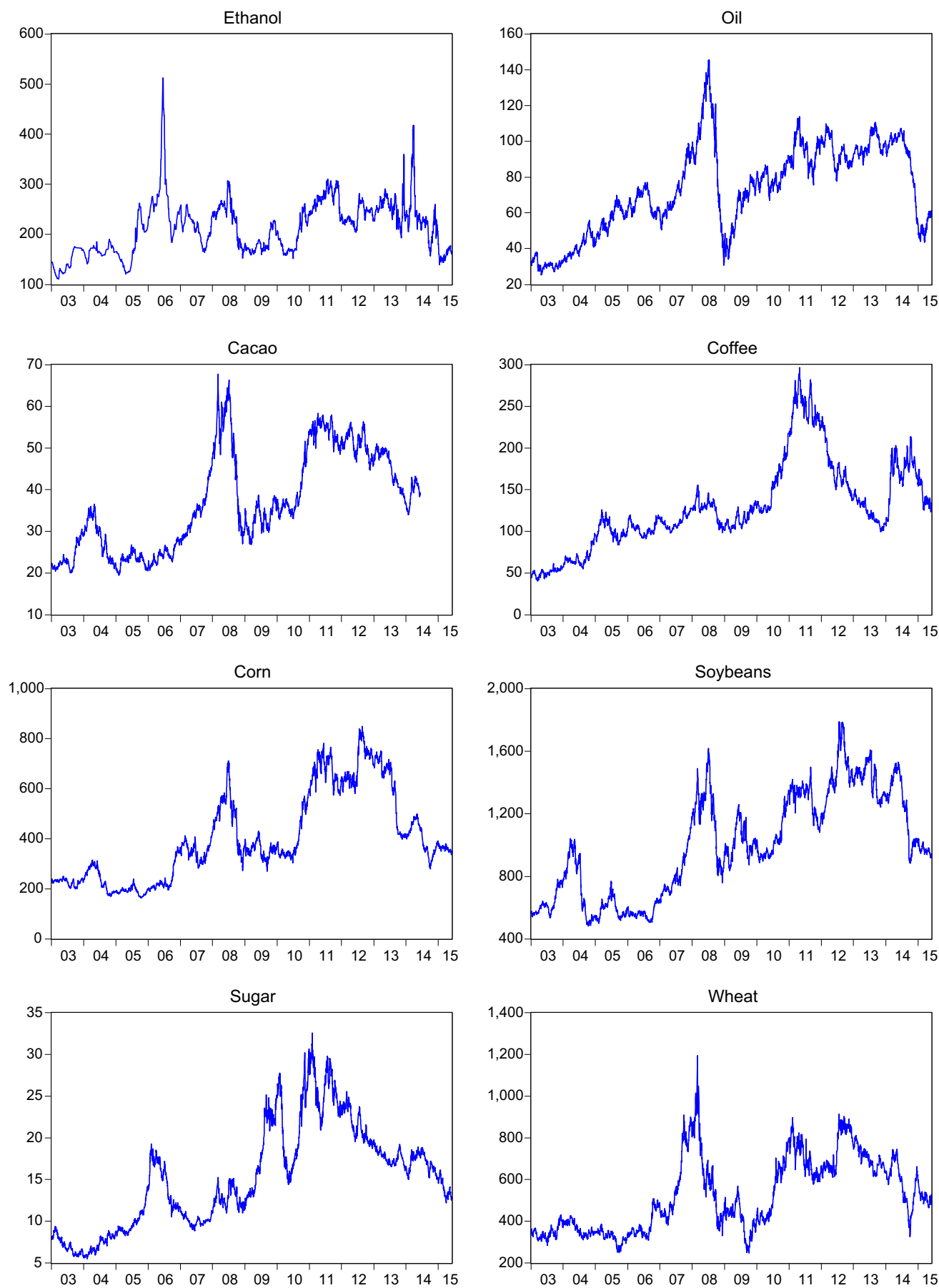

Fig. 1. Spot prices.

$H_{0} 3 \mathrm{~b}:$ Energy $\rightarrow$ food after the first breakpoint: $\beta_{21}^{*}=0$.

$H_{0} 3 \mathrm{c}$ : Energy $\rightarrow$ food after the second breakpoint: $\beta_{21}^{* *}=0$.

$H_{0} 3 \mathrm{~d}$ : Energy $\rightarrow$ food after the third breakpoint: $\beta_{21}^{* * *}$.

$H_{0} 3 \mathrm{e}:$ Energy $\rightarrow$ food after the fourth breakpoint: $\beta_{21}^{* * * *}=0$.

4. Tests of no volatility spillovers from energy to food prices:

$H_{0} 4$ a: Energy $\rightarrow$ food: $a_{12}=g_{12}=0$.

$H_{0} 4 \mathrm{~b}:$ Energy $\rightarrow$ food after the first breakpoint: $a_{12}^{*}=g_{12}^{*}=0$.

$H_{0} 4 \mathrm{c}:$ Energy $\rightarrow$ food after the second breakpoint: $a_{12}^{* *}=g_{12}^{* *}=0$. 

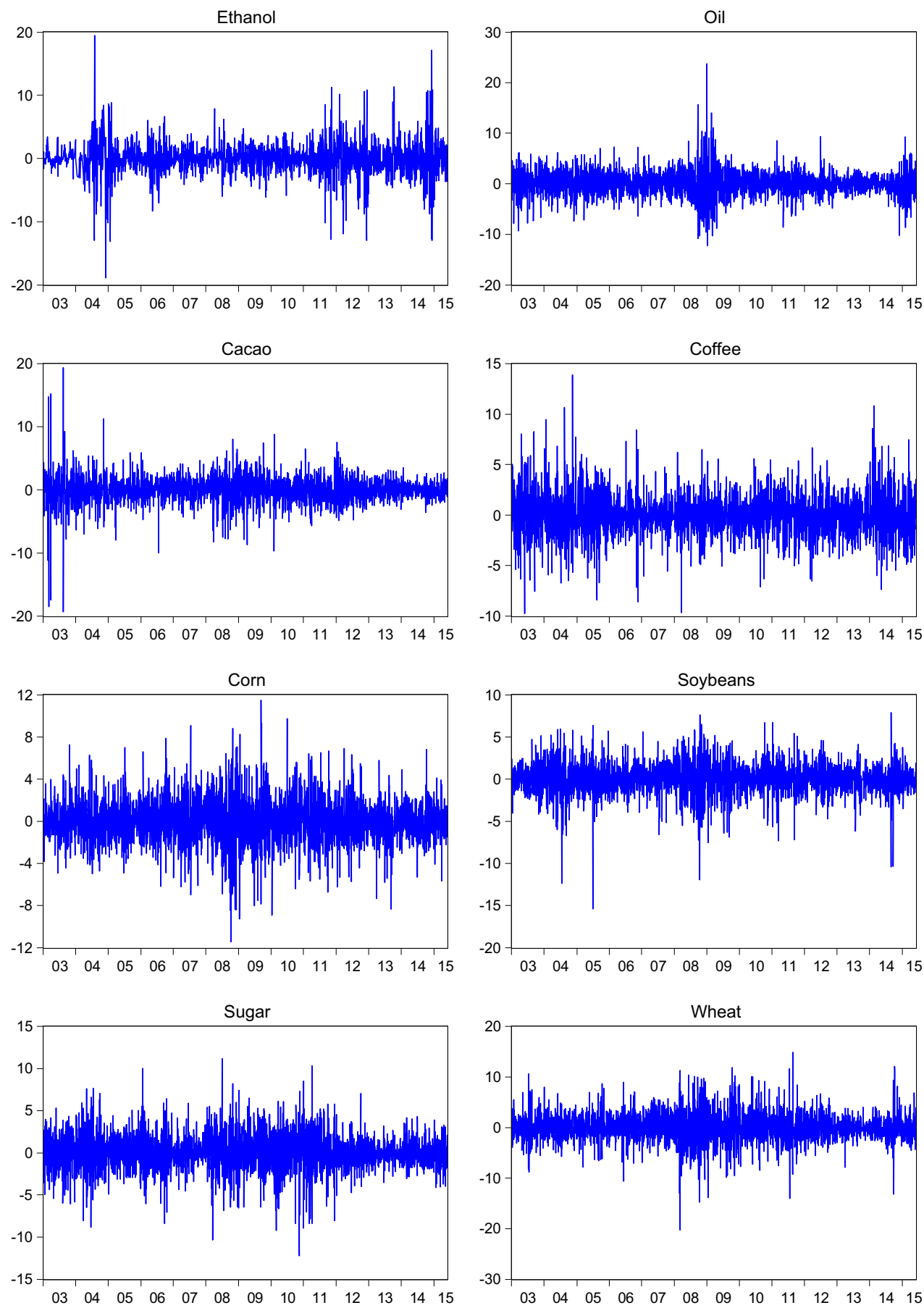

Fig. 2. Spot price returns.

$H_{0} 4 \mathrm{~d}:$ Energy $\rightarrow$ food after the third breakpoint: $a_{12}^{* * *}=g_{12}^{* * *}=0$.

$H_{0} 4 \mathrm{e}:$ Energy $\rightarrow$ food after the fourth breakpoint: $a_{12}^{* * *}=g_{12}^{* * *}=0$.

\subsection{Empirical results}

We select the optimal lag length of the mean equation using the Schwarz information criterion. The pairwise estimates of crossmarket dependence in the conditional mean and variance vary in magnitude and sign. Note that the sign of the cross-market volatilities cannot be established. In order to test the adequacy of the models, Ljung-Box portmanteau tests were performed on the standardised and squared residuals. 
Table 1

Descriptive statistics.

\begin{tabular}{|c|c|c|c|c|c|c|c|c|}
\hline & Oil & Ethanol & Cacao & Coffee & Corn & Soya & Sugar & Wheat \\
\hline & \multicolumn{8}{|c|}{ Full sample $1 / 1 / 2003-6 / 6 / 2015$} \\
\hline Mean & 0.059 & -0.013 & 0.045 & 0.067 & -0.002 & 0.034 & 0.076 & 0.024 \\
\hline Max & 23.714 & 19.482 & 8.173 & 10.801 & 11.509 & 6.713 & 10.288 & 11.682 \\
\hline Min & -12.241 & -18.922 & -6.633 & -9.644 & -11.412 & -15.414 & -12.203 & -20.225 \\
\hline St. Dev. & 2.325 & 2.294 & 1.637 & 1.873 & 2.039 & 1.740 & 2.098 & 2.667 \\
\hline Skewness & 0.717 & -0.291 & 0.239 & 0.098 & -0.070 & -0.799 & -0.205 & -0.194 \\
\hline Kurtosis & 12.232 & 12.961 & 5.033 & 6.294 & 5.587 & 9.121 & 5.932 & 6.889 \\
\hline J-Bera & 8192 & 9342 & 409 & 1022 & 630 & 3756 & 822 & 1433 \\
\hline \multirow[t]{2}{*}{ Obs. } & 2418 & 2418 & 2418 & 2418 & 2418 & 2418 & 2418 & 2418 \\
\hline & \multicolumn{8}{|c|}{ Pre-food crises $1 / 1 / 2003-12 / 31 / 2005$} \\
\hline Mean & 0.193 & -0.056 & 0.047 & 0.049 & -0.128 & 0.009 & 0.182 & -0.004 \\
\hline $\operatorname{Max}$ & 6.967 & 19.485 & 8.168 & 10.676 & 6.983 & 6.340 & 7.632 & 8.644 \\
\hline Min & -7.428 & -18.926 & -6.078 & -8.395 & -4.981 & -15.419 & -8.836 & -6.625 \\
\hline St. Dev. & 2.114 & 2.986 & 1.782 & 2.398 & 1.614 & 2.143 & 2.088 & 2.122 \\
\hline Skewness & -0.040 & -0.625 & 0.304 & -0.027 & -0.049 & -1.341 & -0.077 & 0.164 \\
\hline Kurtosis & 3.703 & 14.701 & 4.325 & 4.288 & 3.905 & 11.642 & 4.703 & 4.518 \\
\hline J-Bera & 8012 & 2412 & 371 & 287 & 146 & 1425 & 509 & 428 \\
\hline \multirow[t]{2}{*}{ Obs. } & 583 & 583 & 583 & 583 & 583 & 583 & 583 & 583 \\
\hline & \multicolumn{8}{|c|}{ Post-food crises $1 / 1 / 2006-6 / 6 / 2015$} \\
\hline Mean & 0.029 & -0.003 & 0.045 & 0.071 & 0.027 & 0.040 & 0.052 & 0.030 \\
\hline $\operatorname{Max}$ & 23.712 & 11.391 & 8.033 & 10.803 & 11.505 & 6.716 & 10.293 & 11.681 \\
\hline Min & -12.252 & -12.972 & -6.630 & -9.642 & -11.414 & -11.965 & -12.201 & -20.223 \\
\hline St. Dev. & 2.370 & 2.105 & 1.603 & 1.732 & 2.124 & 1.634 & 2.101 & 2.777 \\
\hline Skewness & 0.846 & -0.043 & 0.217 & 0.175 & -0.088 & -0.488 & -0.233 & -0.230 \\
\hline Kurtosis & 13.423 & 8.881 & 5.227 & 6.997 & 5.546 & 6.524 & 6.201 & 6.857 \\
\hline J-Bera & 8523 & 2645 & 394 & 1227 & 495 & 1023 & 800 & 1151 \\
\hline Obs. & 1835 & 1835 & 1835 & 1835 & 1835 & 1835 & 1835 & 1835 \\
\hline
\end{tabular}

Note: Descriptive statistics for the whole sample $1 / 1 / 2003-6 / 6 / 2015$, pre-food crisis 1/1/2003-31/12/2005, and post-food crisis sample $1 / 1 / 2006-6 / 6 / 2015$.

Table 2

Sample correlations.

\begin{tabular}{|c|c|c|c|c|c|c|c|c|c|}
\hline & Oil & Ethanol & Stock & Cacao & Coffee & Corn & Soybeans & Sugar & Wheat \\
\hline & \multicolumn{8}{|c|}{ Pre-food crises $1 / 1 / 2003-31 / 12 / 2005$} & \\
\hline Oil & - & & & & & & & & \\
\hline Ethanol & $0.056(0.18)$ & - & & & & & & & \\
\hline Stock & $-0.180(0.00)$ & $0.025(0.54)$ & - & & & & & & \\
\hline Cacao & $0.114(0.01)$ & $-0.066(0.11)$ & $0.046(0.27)$ & - & & & & & \\
\hline Coffee & $0.039(0.35)$ & $-0.020(0.64)$ & $-0.065(0.12)$ & $0.050(0.23)$ & - & & & & \\
\hline Corn & $0.158(0.00)$ & $-0.017(0.69)$ & $0.064(0.12)$ & $0.423(0.00)$ & $0.031(0.46)$ & - & & & \\
\hline Soybeans & $0.115(0.01)$ & $-0.075(0.07)$ & $0.035(0.39)$ & $0.642(0.00)$ & $0.025(0.54)$ & $0.496(0.00)$ & - & & \\
\hline Sugar & $0.045(0.28)$ & $0.001(0.98)$ & $-0.040(0.34)$ & $0.064(0.12)$ & $0.046(0.26)$ & $-0.067(0.11)$ & $0.016(0.70)$ & - & \\
\hline \multirow[t]{2}{*}{ Wheat } & $0.077(0.07)$ & $-0.041(0.33)$ & $-0.008(0.84)$ & $0.284(0.00)$ & $0.031(0.46)$ & $0.394(0.00)$ & $0.278(0.00)$ & $0.106(0.01)$ & - \\
\hline & \multicolumn{8}{|c|}{ Post-food crises $1 / 1 / 2006-6 / 6 / 2015$} & \\
\hline Oil & - & & & & & & & & \\
\hline Ethanol & $0.021(0.30)$ & - & & & & & & & \\
\hline Stock & $0.213(0.00)$ & $-0.013(0.52)$ & - & & & & & & \\
\hline Cacao & $0.385(0.00)$ & $-0.038(0.06)$ & $0.197(0.00)$ & - & & & & & \\
\hline Coffee & $0.061(0.00)$ & $-0.004(0.86)$ & $-0.026(0.20)$ & $0.059(0.00)$ & - & & & & \\
\hline Corn & $0.261(0.00)$ & $0.004(0.84)$ & $0.125(0.00)$ & $0.454(0.00)$ & $0.022(0.27)$ & - & & & \\
\hline Soybeans & $0.277(0.00)$ & $-0.022(0.28)$ & $0.120(0.00)$ & $0.667(0.00)$ & $0.023(0.25)$ & $0.535(0.00)$ & - & & \\
\hline Sugar & $0.206(0.00)$ & $-0.033(0.10)$ & $0.127(0.00)$ & $0.183(0.00)$ & $0.072(0.00)$ & $0.172(0.00)$ & $0.163(0.00)$ & - & \\
\hline Wheat & $0.204(0.00)$ & $-0.011(0.58)$ & $0.097(0.00)$ & $0.352(0.00)$ & $0.010(0.61)$ & $0.498(0.00)$ & $0.362(0.00)$ & $0.169(0.00)$ & - \\
\hline
\end{tabular}


Table 3

Summary results for oil.

\begin{tabular}{|c|c|c|c|c|c|c|c|}
\hline Oil $=>$ & Cacao & Coffee & Corn & Soybeans & Sugar & Wheat & Ethanol \\
\hline$\beta_{12}$ & & - & & & + & & - \\
\hline$\beta_{12}^{*}$ & & & + & & & & \\
\hline$\beta_{12}^{* *}$ & & & & & & & + \\
\hline \multicolumn{8}{|l|}{$\beta_{12}^{* * *}$} \\
\hline$\beta_{12}^{* * * *}$ & & & & & - & & + \\
\hline$a_{21}$ & & $x$ & $x$ & $x$ & & & $x$ \\
\hline$a_{21}^{*}$ & & $\times$ & & & & & \\
\hline$a_{21}^{* *}$ & & $\times$ & & & $\times$ & & $\times$ \\
\hline$a_{21}^{* * *}$ & & $x$ & $\times$ & & & & \\
\hline$a_{21}^{* * * * *}$ & & $\times$ & $\times$ & $\times$ & & & \\
\hline$g_{21}$ & $x$ & $x$ & $x$ & $x$ & $x$ & & $x$ \\
\hline$g_{21}^{*}$ & & $x$ & $x$ & $x$ & & & \\
\hline$g_{21}^{* *}$ & & $x$ & & $x$ & $x$ & $x$ & $x$ \\
\hline$g_{21}^{* * *}$ & $x$ & $\times$ & & & $\times$ & $\times$ & \\
\hline$g_{21}^{* * * *}$ & & $x$ & $x$ & & $x$ & $x$ & \\
\hline Oil. $<=$ & Cacao & Coffee & Corn & Soybeans & Sugar & Wheat & Ethanol \\
\hline$\beta_{21}$ & & & - & - & + & & \\
\hline$\beta_{21}^{*}$ & & & - & & & - & \\
\hline$\beta_{21}^{* *}$ & & & & & & + & - \\
\hline$\beta_{21}^{* * *}$ & + & & & & & & \\
\hline$\beta_{21}^{* * * *}$ & & & + & + & & + & \\
\hline$a_{21}$ & & $x$ & & $\times$ & & & \\
\hline$a_{21}^{*}$ & & & & & $x$ & & $\mathrm{x}$ \\
\hline$a_{21}^{* *}$ & $\times$ & & & & & & \\
\hline$a_{21}^{* * *}$ & & $x$ & $\times$ & & $x$ & & $\mathrm{x}$ \\
\hline$a_{21}^{* * * * *}$ & & & $\times$ & & & & \\
\hline$g_{12}$ & $x$ & $x$ & & & & $x$ & \\
\hline$g_{12}^{*}$ & & $\times$ & $x$ & $x$ & $\times$ & $\times$ & \\
\hline$g_{12}^{* *}$ & & & & $x$ & & $\times$ & \\
\hline$g_{12}^{* * *}$ & & & $\times$ & & $x$ & $x$ & \\
\hline$g_{12}^{* * * * *}$ & & & $x$ & & & $x$ & \\
\hline
\end{tabular}

The exogenous variable to control for business cycle fluctuations is statistically significant, indicating a positive US stock returns effect, as one would expect since this variable can be interpreted as a proxy for financial market sentiment. The estimated volatility spillovers between oil and food prices suggest strong linkages between food and energy markets. As for the conditional variance equations, the estimated "own-market" coefficients are statistically significant and the estimates of $g_{11}$ suggest a high degree of persistence. The estimated VAR-GARCH(1,1) model with associated robust $p$-values and likelihood function values are presented in Tables 3-11. Overall, the results indicate that this specification captures satisfactorily the persistence in returns and squared returns of all the series considered.

Concerning the effect of energy on food, we observe the following. Return spillovers from oil have a negative impact on coffee $\left(\beta_{12}=-0.098\right)$ and on ethanol $(-0.174)$, whilst the effect is positive on sugar $(0.203)$. Return spillovers from ethanol to wheat are also positive (0.038). The food crisis had an impact on return spillovers from oil to corn $\left(\beta_{12}^{*}=0.174\right)$. The oil bubble instead had an impact on spillovers from oil to ethanol $\left(\beta_{12}^{* *}=0.149\right)$. The RFS policy does not appear to have affected spillovers from oil to any of the food commodities considered, with all $\beta_{12}^{* * *}$ being not significantly different from zero, whereas the financial crisis had an effect on spillovers from oil to sugar and ethanol.

Regarding the volatility spillovers from oil to food, the following can be noted. There is evidence of such spillovers in the cases of coffee $\left(\alpha_{21}=0.177\right)$, corn $\left(\alpha_{21}=-0.097\right)$, soybeans $\left(\alpha_{21}=0.098\right)$ and ethanol $\left(\alpha_{21}=0.216\right)$. There are also significant volatility spillovers from ethanol to cacao $\left(\alpha_{21}=0.041\right)$. The food crisis affected only the dynamics between oil and coffee. The oil turbulence period led to a reduction, in absolute value, in spillovers from oil to coffee $\left(\alpha_{21}+\alpha_{21}^{* *}=0.177-0.189=-0.012\right)$, and from oil to ethanol ( -0.023$)$, whereas the effect on sugar was unchanged. The introduction of the RFS policy produced an increase in volatility spillovers from oil to coffee $\left(\alpha_{21}+\alpha_{21}^{* *}=0.359\right)$ and a decrease in those from oil to corn $\left(\alpha_{21}+\alpha_{21}^{* * *}=-0.005\right)$. Finally, the financial crisis had an effect on the spillovers from oil to coffee $\left(\alpha_{21}+\alpha_{21}^{* * * *}=0.270\right)$, corn $(-0.009)$ and soybeans $(0.235)$.

Moving on to the effects of food on energy price returns, the following is noteworthy. Significant mean spillovers are found from $\operatorname{corn}\left(\beta_{21}=-0.022\right)$, soybeans ( -0.015$)$ and sugar $(0.078)$ to oil, and also from sugar to ethanol $\left(\beta_{21}=-0.099\right)$. The food crisis had a negative effect on mean spillovers from corn $\left(\beta_{21}+\beta_{21}^{*}=-0.022-0.132=-0.154\right)$ and wheat $(-0.207)$ to oil. The energy bubble 
Table 4

Summary results for ethanol.

\begin{tabular}{|c|c|c|c|c|c|c|c|}
\hline Eth. $=>$ & Cacao & Coffee & Corn & Soybeans & Sugar & Wheat & Oil \\
\hline$\beta_{12}$ & & & & & & + & \\
\hline \multicolumn{8}{|l|}{$\beta_{12}^{*}$} \\
\hline$\beta_{12}^{* *}$ & & & & & & & - \\
\hline$\beta_{12}^{* * *}$ & - & & & & & & \\
\hline \multicolumn{8}{|l|}{$\beta_{12}^{* * * * *}$} \\
\hline$a_{21}$ & $x$ & & & & & & \\
\hline$a_{21}^{*}$ & & & $x$ & $\times$ & & & $x$ \\
\hline$a_{21}^{* *}$ & $x$ & & $x$ & & & $x$ & \\
\hline$a_{21}^{* * *}$ & $x$ & & $x$ & & $x$ & & $x$ \\
\hline$a_{21}^{* * * *}$ & & $x$ & & & & & \\
\hline$g_{21}$ & $x$ & & & $x$ & & & \\
\hline$g_{21}^{*}$ & & $x$ & & $x$ & & $x$ & \\
\hline$g_{21}^{* *}$ & & & & $\times$ & & $x$ & \\
\hline$g_{21}^{* * *}$ & $x$ & & & & & $x$ & \\
\hline$g_{21}^{* * * * *}$ & & & $x$ & $x$ & & & \\
\hline Eth. $=<$ & Cacao & Coffee & Corn & Soybeans & Sugar & Wheat & Oil \\
\hline$\beta_{21}$ & & & & & - & & - \\
\hline$\beta_{21}^{*}$ & & & & + & & & \\
\hline$\beta_{21}^{* *}$ & & & & & + & & + \\
\hline \multicolumn{8}{|l|}{$\beta_{21}^{* * * *}$} \\
\hline$\beta_{21}^{* * * *}$ & & & & & + & & + \\
\hline$a_{12}$ & & $x$ & & & & & $x$ \\
\hline$a_{12}^{*}$ & $\times$ & & $x$ & & & & \\
\hline$a_{12}^{* *}$ & & $x$ & & & & & $x$ \\
\hline$a_{12}^{* * *}$ & & & $x$ & $\times$ & & & \\
\hline$a_{12}^{* * * *}$ & & $x$ & $x$ & & & & \\
\hline$g_{12}$ & $x$ & & $x$ & $x$ & & & $\times$ \\
\hline$g_{12}^{*}$ & & & $x$ & $\times$ & & & \\
\hline$g_{12}^{* *}$ & $x$ & & & $\times$ & & & $x$ \\
\hline$g_{12}^{* * *}$ & & & $\times$ & $x$ & & $x$ & \\
\hline$g_{12}^{* * * * *}$ & $x$ & $x$ & & $x$ & & & \\
\hline
\end{tabular}

increased spillovers in mean from wheat to oil $\left(\beta_{21}^{* * *}=0.131\right)$. The 2008 financial crisis had a significant impact on the return spillover for $\operatorname{corn}\left(\beta_{21}+\beta_{21}^{* * * *}=-0.022+0.133=0.111\right)$, soybeans $(0.061)$ and wheat $(0.203)$. The RFS policy only had an impact on the spillover from cacao to oil $\left(\beta_{21}^{* * *}=0.181\right)$.

Regarding volatility spillovers from food to energy price returns, we find evidence of spillovers only in the case of coffee and soybeans. The RFS policy had an impact on volatility spillovers from coffee, corn and sugar towards oil, and corn prices and from soybeans to ethanol prices. The financial crisis also had an impact on volatility spillovers from coffee and corn to ethanol prices, and from corn to oil prices. ${ }^{6}$

Finally, the conditional correlations (Figs. 3 and 4) also suggest changes in the relationship between energy and food prices, in particular after the financial crisis, which confirms the importance of estimating a model allowing for breaks in the dynamic linkages between food and energy prices. Overall, our results show that all four breaks considered affected both mean and variance spillovers, the financial crisis having the most significant effects.

\section{Conclusions}

This paper has investigated the mean and volatility spillovers between energy (ethanol and oil) and six selected food prices (cacao, coffee, corn, soybeans, sugar and wheat) by estimating a VAR-GARCH model with a BEKK representation. Moreover, it has examined the possible effects of four recent events that might have resulted in shifts in the model parameters by including dummy variables in both the conditional mean and variance equations. The extensive dataset analysed, the focus on both first- and secondmoment linkages and the incorporation of structural breaks into the multivariate GARCH specification all represent original contributions to the existing literature. Although the results are relatively mixed, they confirm that food and energy prices are tightly

\footnotetext{
${ }^{6}$ Consistent patterns emerge from both the estimated conditional volatility cross-parameters $\left(g_{21}\right.$ and $\left.g_{12}\right)$ and the volatility spillover parameters ( $a_{21}$ and $\left.a_{12}\right)$.
} 
Table 5

Estimated VAR-GARCH(1,1) model, oil-cacao and ethanol-cacao.

\begin{tabular}{|c|c|c|c|c|c|c|c|c|c|}
\hline & \multicolumn{2}{|c|}{ Oil $=>$ Cacao } & \multicolumn{2}{|c|}{ Eth. $=>$ Cacao } & & \multicolumn{2}{|c|}{ Cacao. $=>$ Oil } & \multicolumn{2}{|c|}{ Cacao. $=>$ Eth } \\
\hline & Coef. & $p$-Value & Coef. & $p$-Value & & Coef. & $p$-Value & Coef. & $p$-Value \\
\hline \multicolumn{10}{|c|}{ Conditional mean } \\
\hline$\alpha_{1}$ & 0.027 & $(0.473)$ & -0.003 & $(0.943)$ & $\alpha_{2}$ & 0.028 & $(0.391)$ & 0.034 & $(0.323)$ \\
\hline$\beta_{11}$ & -0.004 & $(0.790)$ & 0.105 & $(0.000)$ & $\beta_{22}$ & -0.020 & $(0.374)$ & 0.006 & $(0.664)$ \\
\hline$\beta_{12}$ & 0.024 & $(0.432)$ & -0.020 & $(0.427)$ & $\beta_{21}$ & 0.025 & $(0.120)$ & -0.051 & $(0.442)$ \\
\hline$\beta_{12}^{*}$ & 0.035 & $(0.738)$ & 0.138 & $(0.080)$ & $\beta_{21}^{*}$ & -0.085 & $(0.252)$ & -0.057 & $(0.280)$ \\
\hline$\beta_{12}^{* *}$ & -0.044 & $(0.500)$ & -0.041 & $(0.423)$ & $\beta_{21}^{* *}$ & -0.011 & $(0.848)$ & 0.057 & $(0.399)$ \\
\hline$\beta_{12}^{* * *}$ & 0.015 & $(0.892)$ & -0.216 & $(0.005)$ & $\beta_{21}^{* * *}$ & 0.181 & $(0.011)$ & 0.082 & $(0.157)$ \\
\hline$\beta_{12}^{* * * *}$ & -0.016 & $(0.837)$ & 0.106 & $(0.063)$ & $\beta_{21}^{* * * *}$ & -0.020 & $(0.654)$ & 0.025 & $(0.725)$ \\
\hline$\gamma_{1}$ & 0.064 & $(0.008)$ & -0.011 & $(0.734)$ & $\gamma_{2}$ & 0.078 & $(0.000)$ & 0.093 & $(0.000)$ \\
\hline \multicolumn{10}{|c|}{ Conditional variance } \\
\hline$c_{11}$ & 0.501 & $(0.000)$ & 0.294 & $(0.000)$ & $c_{22}$ & 0.000 & $(0.999)$ & 0.146 & $(0.000)$ \\
\hline$c_{12}$ & 0.000 & (0.999) & -0.031 & $(0.379)$ & & & & & \\
\hline$a_{11}$ & 0.174 & $(0.000)$ & 0.908 & $(0.000)$ & $a_{22}$ & 0.229 & $(0.000)$ & -0.198 & $(0.000)$ \\
\hline$a_{21}$ & -0.052 & $(0.231)$ & 0.041 & $(0.005)$ & $a_{12}$ & 0.014 & $(0.441)$ & 0.015 & $(0.753)$ \\
\hline$a_{21}^{*}$ & -0.017 & $(0.783)$ & 0.043 & $(0.168)$ & $a_{12}^{*}$ & 0.102 & $(0.226)$ & -0.106 & $(0.016)$ \\
\hline$a_{21}^{* *}$ & 0.058 & $(0.241)$ & -0.042 & $(0.044)$ & $a_{12}^{* *}$ & -0.191 & $(0.042)$ & 0.014 & $(0.769)$ \\
\hline$a_{21}^{* * *}$ & -0.044 & $(0.605)$ & -0.077 & $(0.018)$ & $a_{12}^{* * *}$ & 0.047 & $(0.576)$ & 0.093 & $(0.106)$ \\
\hline$a_{21}^{* * * *}$ & 0.120 & $(0.200)$ & 0.013 & $(0.582)$ & $a_{12}^{*} * * *$ & -0.062 & $(0.457)$ & 0.000 & $(0.992)$ \\
\hline$g_{11}$ & 0.978 & $(0.000)$ & 0.410 & $(0.000)$ & $g_{22}$ & 0.912 & $(0.000)$ & -0.198 & $(0.000)$ \\
\hline$g_{21}$ & 0.227 & $(0.000)$ & 0.045 & $(0.044)$ & $g_{12}$ & -0.140 & $(0.000)$ & -0.071 & $(0.003)$ \\
\hline$g_{21}^{*}$ & -0.067 & $(0.527)$ & 0.157 & $(0.162)$ & $g_{12}^{*}$ & 0.102 & $(0.226)$ & 0.016 & $(0.462)$ \\
\hline$g_{21}^{* * *}$ & -0.106 & $(0.314)$ & -0.072 & $(0.276)$ & $g_{12}^{* *}$ & 0.064 & $(0.420)$ & 0.053 & $(0.016)$ \\
\hline$g_{21}^{* * *}$ & -0.114 & $(0.027)$ & -0.267 & $(0.015)$ & $g_{12}^{* * *}$ & 0.056 & $(0.064)$ & 0.001 & $(0.978)$ \\
\hline$g_{21}^{* * * *}$ & -0.006 & $(0.915)$ & 0.130 & $(0.082)$ & $g_{12}^{* * * *}$ & 0.003 & $(0.937)$ & 0.054 & $(0.007)$ \\
\hline Log-lik & \multicolumn{2}{|l|}{-19053.91} & \multicolumn{2}{|l|}{-10954.14} & & & & & \\
\hline Qoil(10) & \multicolumn{2}{|l|}{5.815} & & & \multicolumn{3}{|l|}{$\operatorname{Arch}(10)_{\text {Oil }}$} & \multicolumn{2}{|l|}{3.689} \\
\hline$Q_{O i l(10)}^{2}$ & \multicolumn{2}{|l|}{11.982} & & & $\operatorname{Arch}(10)_{\text {Cacao }}$ & & & \multicolumn{2}{|l|}{2.329} \\
\hline \multicolumn{3}{|l|}{$Q_{E t h .(10)}$} & \multicolumn{2}{|l|}{7.576} & $\operatorname{Arch}(10)_{\text {Ethanol }}$ & & & \multirow{2}{*}{\multicolumn{2}{|c|}{0.753}} \\
\hline$Q_{E t h .(10)}^{2}$ & & & 13.312 & & & & & & \\
\hline$Q_{\text {Cacao }(10)}$ & \multicolumn{2}{|l|}{10.337} & \multicolumn{2}{|l|}{16.423} & & & & & \\
\hline$Q_{\text {Cacao }(10)}^{2}$ & \multicolumn{2}{|l|}{12.334} & \multicolumn{3}{|l|}{13.491} & & & & \\
\hline
\end{tabular}

Note: Standard errors (S.E.) are calculated using the quasi-maximum likelihood method, which is robust to the distribution of the underlying residuals. Parameters not statistically significant at the $5 \%$ level are not reported. $Q_{(10)}$ and $Q_{(10)}^{2}$ are, respectively, the Ljung-Box test (1978) of significance of autocorrelations of 10 lags in the standardised and standardised squared residuals. Parameters $\beta_{21}$ and $a_{12}$ measure the causality effect of oil (ethanol) on food commodities, and the causality in variance effect, respectively. The effects of the $1 / 1 / 2006,20 / 3 / 2004,6 / 6 / 2008$ and $15 / 8 / 2004$ crises are measured by $\left(\beta_{12}+\beta_{12}^{*}\right),\left(\beta_{12}+\beta_{12}^{* *}\right),\left(\beta_{12}+\beta_{12}^{* *}\right)$ and $\left(\beta_{12}+\beta_{12}^{* * * *}\right)$, respectively. The same applies to the effects on food volatilities. The covariance stationary condition is satisfied by all the estimated models, all the eigenvalues of $A_{11} \otimes A_{11}+G_{11} \otimes G_{11}$ being less than one in modulus. Note that in the conditional variance equation, the sign of the parameters is not relevant. Numbers are rounded to the third decimal.

Table 6

Estimated VAR-GARCH(1,1) model, oil-coffee and ethanol-coffee.

\begin{tabular}{|c|c|c|c|c|c|c|c|c|c|}
\hline & \multicolumn{2}{|c|}{ Oil $=>$ Coffee } & \multicolumn{2}{|c|}{ Eth. $=>$ Coffee } & & \multicolumn{2}{|c|}{ Coffee $=>$ Oil } & \multicolumn{2}{|c|}{ Coffee $=>$ Eth.} \\
\hline & Coef. & $p$-Value & Coef. & $p$-Value & & Coef. & $p$-Value & Coef. & $p$-Value \\
\hline \multicolumn{10}{|c|}{ Conditional mean } \\
\hline$\alpha_{1}$ & 0.026 & $(0.494)$ & -0.002 & $(0.948)$ & $\alpha_{2}$ & 0.040 & $(0.245)$ & 0.038 & $(0.382)$ \\
\hline$\beta_{11}$ & -0.048 & $(0.037)$ & 0.117 & $(0.000)$ & $\beta_{22}$ & 0.025 & (0.109) & 0.025 & $(0.123)$ \\
\hline$\beta_{12}$ & -0.098 & $(0.025)$ & -0.018 & $(0.336)$ & $\beta_{21}$ & 0.113 & $(0.055)$ & -0.125 & $(0.162)$ \\
\hline$\beta_{12}^{*}$ & -0.168 & $(0.074)$ & 0.014 & $(0.879)$ & $\beta_{21}^{*}$ & 0.035 & $(0.550)$ & -0.006 & $(0.879)$ \\
\hline$\beta_{12}^{* *}$ & 0.127 & $(0.052)$ & -0.021 & (0.608) & $\beta_{21}^{* *}$ & -0.013 & $(0.843)$ & 0.116 & $(0.183)$ \\
\hline$\beta_{12}^{* * *}$ & 0.154 & $(0.110)$ & 0.033 & $(0.691)$ & $\beta_{21}^{* * *}$ & -0.083 & $(0.103)$ & 0.083 & $(0.108)$ \\
\hline$\beta_{12}^{* * * *}$ & 0.129 & $(0.114)$ & -0.043 & $(0.440)$ & $\beta_{21}^{* * * * *}$ & 0.006 & $(0.932)$ & 0.029 & (0.697) \\
\hline
\end{tabular}


Table 6 (continued)

\begin{tabular}{|c|c|c|c|c|c|c|c|c|c|}
\hline & \multicolumn{2}{|c|}{ Oil $=>$ Coffee } & \multicolumn{2}{|c|}{ Eth. $=>$ Coffee } & & \multicolumn{2}{|c|}{ Coffee $=>$ Oil } & \multicolumn{2}{|c|}{ Coffee $=>$ Eth } \\
\hline & Coef. & $p$-Value & Coef. & $p$-Value & & Coef. & $p$-Value & Coef. & $p$-Value \\
\hline$\gamma_{1}$ & 0.063 & $(0.107)$ & -0.018 & $(0.534)$ & $\gamma_{2}$ & 0.108 & $(0.000)$ & 0.159 & $(0.000)$ \\
\hline \multicolumn{10}{|c|}{ Conditional variance } \\
\hline$c_{11}$ & 0.003 & $(0.000)$ & 0.329 & $(0.000)$ & $c_{22}$ & 0.994 & $(0.000)$ & 0.000 & $(1.000)$ \\
\hline$c_{12}$ & -0.001 & $(0.000)$ & -0.135 & $(0.000)$ & & & & & \\
\hline$a_{11}$ & 0.232 & $(0.000)$ & 0.412 & $(0.000)$ & $a_{22}$ & 0.260 & $(0.000)$ & -0.123 & $(0.000)$ \\
\hline$a_{21}$ & 0.177 & $(0.000)$ & 0.013 & $(0.434)$ & $a_{12}$ & -0.203 & $(0.049)$ & 0.152 & $(0.000)$ \\
\hline$a_{21}^{*}$ & -0.038 & $(0.002)$ & 0.035 & $(0.804)$ & $a_{12}^{*}$ & -0.014 & $(0.899)$ & 0.047 & $(0.177)$ \\
\hline$a_{21}^{* *}$ & -0.189 & $(0.019)$ & 0.023 & $(0.682)$ & $a_{12}^{* *}$ & 0.153 & $(0.110)$ & -0.122 & $(0.000)$ \\
\hline$a_{21}^{* * *}$ & 0.182 & $(0.000)$ & -0.194 & $(0.102)$ & $a_{12}^{* * *}$ & 0.197 & $(0.021)$ & -0.026 & $(0.539)$ \\
\hline$a_{21}^{* * * * *}$ & 0.093 & $(0.000)$ & 0.227 & $(0.002)$ & $a_{12}^{* * * *}$ & 0.047 & $(0.690)$ & -0.148 & $(0.001)$ \\
\hline$g_{11}$ & 0.964 & $(0.000)$ & 0.903 & $(0.000)$ & $g_{22}$ & 0.757 & $(0.000)$ & 0.989 & $(0.000)$ \\
\hline$g_{21}$ & -0.116 & $(0.000)$ & 0.005 & $(0.240)$ & $g_{12}$ & 0.397 & $(0.000)$ & -0.027 & $(0.222)$ \\
\hline$g_{21}^{*}$ & -0.038 & $(0.002)$ & 0.067 & $(0.001)$ & $g_{12}^{*}$ & -0.347 & $(0.000)$ & -0.021 & $(0.191)$ \\
\hline$g_{21}^{* *}$ & -0.189 & $(0.019)$ & -0.002 & $(0.848)$ & $g_{12}^{* *}$ & -0.055 & $(0.234)$ & 0.016 & $(0.444)$ \\
\hline$g_{21}^{* * *}$ & 0.182 & $(0.000)$ & -0.039 & $(0.071)$ & $g_{12}^{* * *}$ & 0.002 & $(0.972)$ & -0.008 & $(0.738)$ \\
\hline$g_{21}^{* * * *}$ & -0.275 & $(0.000)$ & -0.021 & $(0.290)$ & $g_{12}^{* * * * *}$ & -0.050 & $(0.294)$ & 0.056 & $(0.002)$ \\
\hline Log-lik & -11183.76 & & -10907.15 & & & & & & \\
\hline Q Oil(10) & 4.791 & & & & $\operatorname{Arch}(10)_{\text {Oil }}$ & & & 1.067 & \\
\hline$Q_{O i l(10)}^{2}$ & 12.852 & & & & $\operatorname{Arch}(10)_{C o f f e e}$ & & & 2.402 & \\
\hline$Q_{E t h .(10)}$ & & & 16.495 & & $\operatorname{Arch}(10)_{\text {Ethanol }}$ & & & 1.001 & \\
\hline$Q_{E t h .(10)}^{2}$ & & & 16.126 & & & & & & \\
\hline$Q_{\text {Coffee }(10)}$ & 11.755 & & 9.769 & & & & & & \\
\hline$Q_{\text {Coffee(10) }}^{2}$ & 11.572 & & 9.981 & & & & & & \\
\hline
\end{tabular}

Note: See notes in Table 5.

interconnected and also provide clear evidence that the recent turbulence in the world economy has significantly affected their linkages. Both the RFS policy introduced in the US in 2005 and global shocks, such as the food, oil and recent financial crisis appear to have had an impact on the dynamic interactions between energy and food prices. Previous studies had not allowed for the possibility of such parameter instabilities and had therefore overlooked a very important aspect of the food-energy prices nexus, which raises questions about the reliability of their results. The current study addresses directly this issue by modelling shifts in both mean and volatility spillovers between food and energy prices, and hence provides more robust results which can also be informative for policy-makers.

Table 7

Estimated VAR-GARCH(1,1) model, oil-corn and ethanol-corn.

\begin{tabular}{|c|c|c|c|c|c|c|c|c|c|}
\hline & \multicolumn{2}{|c|}{ Oil $=>$ Corn } & \multicolumn{2}{|c|}{ Eth. $=>$ Corn } & & \multicolumn{2}{|c|}{ Corn $=>$ Oil } & \multicolumn{2}{|c|}{ Corn $=>$ Eth } \\
\hline & Coef. & $p$-Value & Coef. & $p$-Value & & Coef. & $p$-Value & Coef. & $p$-Value \\
\hline \multicolumn{10}{|c|}{ Conditional mean } \\
\hline$\alpha_{1}$ & 0.025 & $(0.498)$ & -0.077 & $(0.036)$ & $\alpha_{2}$ & 0.017 & $(0.536)$ & 0.006 & $(0.873)$ \\
\hline$\beta_{11}$ & -0.011 & $(0.375)$ & 0.102 & $(0.000)$ & $\beta_{22}$ & 0.001 & $(0.958)$ & -0.002 & $(0.922)$ \\
\hline$\beta_{12}$ & 0.026 & $(0.363)$ & -0.007 & $(0.776)$ & $\beta_{21}$ & -0.022 & $(0.005)$ & -0.094 & $(0.188)$ \\
\hline$\beta_{12}^{*}$ & 0.174 & $(0.043)$ & -0.094 & $(0.183)$ & $\beta_{21}^{*}$ & -0.132 & $(0.015)$ & -0.158 & $(0.058)$ \\
\hline$\beta_{12}^{* *}$ & -0.092 & $(0.072)$ & -0.020 & $(0.689)$ & $\beta_{21}^{* *}$ & -0.021 & $(0.302)$ & 0.059 & $(0.449)$ \\
\hline$\beta_{12}^{* * *}$ & -0.060 & $(0.437)$ & 0.098 & $(0.115)$ & $\beta_{21}^{* * *}$ & 0.039 & $(0.650)$ & 0.196 & $(0.067)$ \\
\hline$\beta_{12}^{* * * *}$ & -0.039 & $(0.389)$ & -0.009 & $(0.874)$ & $\beta_{21}^{* * * *}$ & 0.133 & $(0.005)$ & 0.063 & $(0.454)$ \\
\hline$\gamma_{1}$ & 0.055 & $(0.042)$ & 0.005 & $(0.858)$ & $\gamma_{2}$ & 0.034 & $(0.085)$ & $\begin{array}{l}0.018 \\
\text { (contint }\end{array}$ & $\begin{array}{c}(0.536) \\
\text { next pag }\end{array}$ \\
\hline
\end{tabular}


Table 7 (continued)

\begin{tabular}{|c|c|c|c|c|c|c|c|c|c|}
\hline & \multicolumn{2}{|c|}{ Oil $=>$ Corn } & \multicolumn{2}{|c|}{ Eth. $=>$ Corn } & & \multicolumn{2}{|c|}{ Corn $=>$ Oil } & \multicolumn{2}{|c|}{ Corn $=>$ Eth } \\
\hline & Coef. & $p$-Value & Coef. & $p$-Value & & Coef. & $p$-Value & Coef. & $p$-Value \\
\hline \multicolumn{10}{|c|}{ Conditional variance } \\
\hline$c_{11}$ & 0.143 & $(0.053)$ & 0.181 & $(0.000)$ & $c_{22}$ & 0.323 & $(0.000)$ & 0.155 & $(0.262)$ \\
\hline$c_{12}$ & -0.038 & $(0.105)$ & 0.051 & $(0.733)$ & & & & & \\
\hline$a_{11}$ & 0.184 & $(0.000)$ & 0.384 & $(0.000)$ & $a_{22}$ & 0.226 & $(0.000)$ & -0.119 & $(0.022)$ \\
\hline$a_{21}$ & -0.097 & $(0.001)$ & -0.007 & $(0.779)$ & $a_{12}$ & 0.002 & $(0.812)$ & 0.055 & $(0.276)$ \\
\hline$a_{21}^{*}$ & -0.017 & $(0.633)$ & -0.271 & $(0.000)$ & $a_{12}^{*}$ & -0.002 & $(0.964)$ & 0.131 & $(0.002)$ \\
\hline$a_{21}^{* *}$ & 0.008 & $(0.840)$ & 0.146 & $(0.024)$ & $a_{12}^{* *}$ & 0.038 & $(0.151)$ & -0.044 & $(0.350)$ \\
\hline$a_{21}^{* * *}$ & 0.092 & $(0.023)$ & 0.217 & $(0.000)$ & $a_{12}^{* * *}$ & 0.128 & $(0.000)$ & -0.294 & $(0.001)$ \\
\hline$a_{21}^{* * * * *}$ & 0.088 & $(0.036)$ & 0.134 & $(0.070)$ & $a_{12}^{* * * *}$ & -0.157 & $(0.000)$ & 0.090 & $(0.042)$ \\
\hline$g_{11}$ & 0.979 & $(0.000)$ & 0.920 & $(0.000)$ & $g_{22}$ & 0.953 & $(0.000)$ & 0.988 & $(0.000)$ \\
\hline$g_{21}$ & 0.039 & $(0.003)$ & -0.002 & $(0.885)$ & $g_{12}$ & -0.004 & $(0.221)$ & -0.031 & $(0.003)$ \\
\hline$g_{21}^{*}$ & -0.075 & $(0.000)$ & -0.019 & $(0.376)$ & $g_{12}^{*}$ & 0.050 & $(0.000)$ & -0.031 & $(0.003)$ \\
\hline$g_{21}^{* *}$ & -0.024 & $(0.061)$ & 0.011 & $(0.161)$ & $g_{12}^{* *}$ & 0.006 & $(0.464)$ & 0.007 & $(0.773)$ \\
\hline$g_{21}^{* * *}$ & -0.047 & $(0.103)$ & 0.000 & (0.994) & $g_{12}^{* * *}$ & 0.128 & $(0.000)$ & 0.137 & $(0.000)$ \\
\hline$g_{21}^{* * * * *}$ & 0.090 & $(0.000)$ & 0.030 & $(0.004)$ & $g_{12}^{* * * *}$ & -0.157 & $(0.000)$ & -0.084 & $(0.315)$ \\
\hline Log-lik & \multicolumn{2}{|c|}{-21004.99} & \multicolumn{2}{|c|}{-19578.51} & & & & & \\
\hline$Q_{O i l(10)}$ & \multicolumn{2}{|c|}{5.058} & & & \multicolumn{3}{|l|}{$\operatorname{Arch}(10)_{O i l}$} & \multicolumn{2}{|l|}{2.345} \\
\hline$Q_{O i l(10)}^{2}$ & \multicolumn{2}{|l|}{7.482} & & & $\operatorname{Arch}(10)_{C o r n}$ & & & \multicolumn{2}{|l|}{1.595} \\
\hline$Q_{E t h .(10)}$ & & & \multicolumn{2}{|l|}{16.412} & $\operatorname{Arch}(10)_{\text {Ethanol }}$ & & & \multirow{2}{*}{\multicolumn{2}{|c|}{1.445}} \\
\hline$Q_{E t h .(10)}^{2}$ & & & 12.735 & & & & & & \\
\hline$Q_{\text {Corn }(10)}$ & \multicolumn{2}{|l|}{8.377} & \multicolumn{2}{|l|}{3.801} & & & & & \\
\hline$Q_{\text {Corn(10) }}^{2}$ & \multicolumn{2}{|l|}{14.969} & \multicolumn{3}{|l|}{16.464} & & & & \\
\hline
\end{tabular}

Note: See notes in Table 5.

Table 8

Estimated VAR-GARCH(1,1) model, oil-soybeans and ethanol-soybeans.

\begin{tabular}{|c|c|c|c|c|c|c|c|c|c|}
\hline & \multicolumn{2}{|c|}{ Oil = > Soy } & \multicolumn{2}{|c|}{ Eth. $=>$ Soy } & & \multicolumn{2}{|c|}{ Soy. $=>$ Oil } & \multicolumn{2}{|c|}{ Soy. = > Eth. } \\
\hline & Coef. & $p$-Value & Coef. & $p$-Value & & Coef. & $p$-Value & Coef. & $p$-Value \\
\hline \multicolumn{10}{|c|}{ Conditional mean } \\
\hline$\alpha_{1}$ & 0.026 & $(0.468)$ & -0.018 & $(0.597)$ & $\alpha_{2}$ & 0.013 & $(0.590)$ & 0.025 & $(0.491)$ \\
\hline$\beta_{11}$ & -0.008 & $(0.506)$ & 0.119 & $(0.000)$ & $\beta_{22}$ & -0.033 & $(0.002)$ & -0.041 & $(0.019)$ \\
\hline$\beta_{12}$ & -0.005 & $(0.846)$ & -0.009 & $(0.802)$ & $\beta_{21}$ & -0.015 & $(0.042)$ & -0.009 & $(0.892)$ \\
\hline$\beta_{12}^{*}$ & 0.156 & $(0.079)$ & -0.057 & $(0.542)$ & $\beta_{21}^{*}$ & -0.053 & $(0.178)$ & 0.142 & $(0.012)$ \\
\hline$\beta_{12}^{* *}$ & -0.015 & $(0.665)$ & 0.018 & $(0.754)$ & $\beta_{21}^{* *}$ & 0.032 & $(0.322)$ & -0.095 & $(0.164)$ \\
\hline$\beta_{12}^{* * *}$ & -0.090 & $(0.308)$ & -0.098 & $(0.263)$ & $\beta_{21}^{* * *}$ & -0.055 & $(0.248)$ & -0.028 & $(0.607)$ \\
\hline$\beta_{12}^{* * * *}$ & -0.042 & $(0.368)$ & 0.129 & $(0.080)$ & $\beta_{21}^{* * * *}$ & 0.076 & $(0.029)$ & -0.105 & $(0.155)$ \\
\hline$\gamma_{1}$ & 0.031 & $(0.241)$ & -0.007 & $(0.816)$ & $\gamma_{2}$ & 0.056 & $(0.000)$ & 0.121 & $(0.000)$ \\
\hline \multicolumn{10}{|c|}{ Conditional variance } \\
\hline$c_{11}$ & 0.147 & $(0.000)$ & 0.164 & $(0.000)$ & $c_{22}$ & 0.197 & $(0.056)$ & 0.000 & $(1.000)$ \\
\hline$c_{12}$ & 0.173 & $(0.064)$ & -0.922 & $(0.000)$ & & & & & \\
\hline$a_{11}$ & 0.191 & $(0.000)$ & 0.402 & $(0.000)$ & $a_{22}$ & 0.229 & $(0.000)$ & 0.327 & $(0.000)$ \\
\hline$a_{21}$ & 0.098 & $(0.022)$ & 0.037 & $(0.394)$ & $a_{12}$ & 0.002 & $(0.807)$ & -0.060 & $(0.408)$ \\
\hline$a_{21}^{*}$ & -0.162 & $(0.102)$ & 0.360 & $(0.028)$ & $a_{12}^{*}$ & -0.031 & $(0.503)$ & 0.074 & $(0.328)$ \\
\hline$a_{21}^{* *}$ & -0.020 & $(0.689)$ & -0.145 & $(0.170)$ & $a_{12}^{* *}$ & 0.039 & $(0.352)$ & 0.055 & $(0.496)$ \\
\hline$a_{21}^{* * *}$ & 0.044 & $(0.686)$ & -0.185 & $(0.059)$ & $a_{12}^{* * *}$ & -0.054 & $(0.395)$ & -0.127 & $(0.030)$ \\
\hline$a_{21}^{* * * *}$ & 0.137 & $(0.048)$ & -0.358 & $(0.000)$ & $a_{12}^{* * * *}$ & 0.012 & $(0.830)$ & 0.118 & $(0.249)$ \\
\hline
\end{tabular}


Table 8 (continued)

\begin{tabular}{|c|c|c|c|c|c|c|c|c|c|}
\hline & \multicolumn{2}{|l|}{ Oil $=>$ Soy } & \multicolumn{2}{|c|}{ Eth. $=>$ Soy. } & & \multicolumn{2}{|c|}{ Soy. $=>$ Oil } & \multicolumn{2}{|c|}{ Soy. = > Eth. } \\
\hline & Coef. & $p$-Value & Coef. & $p$-Value & & Coef. & $p$-Value & Coef. & $p$-Value \\
\hline$g_{11}$ & 0.980 & $(0.000)$ & 0.909 & $(0.000)$ & $g_{22}$ & 0.956 & $(0.000)$ & 0.733 & $(0.000)$ \\
\hline$g_{21}$ & -0.044 & $(0.001)$ & 0.144 & $(0.000)$ & $g_{12}$ & 0.002 & $(0.471)$ & -0.181 & $(0.000)$ \\
\hline$g_{21}^{*}$ & 0.148 & $(0.000)$ & -0.343 & $(0.001)$ & $g_{12}^{*}$ & -0.098 & $(0.000)$ & 0.315 & $(0.000)$ \\
\hline$g_{21}^{* *}$ & -0.079 & $(0.000)$ & 0.251 & $(0.000)$ & $g_{12}^{* *}$ & 0.087 & $(0.000)$ & -0.186 & $(0.001)$ \\
\hline$g_{21}^{* * *}$ & -0.022 & $(0.285)$ & -0.185 & $(0.059)$ & $g_{12}^{* * *}$ & 0.016 & $(0.300)$ & 0.181 & $(0.000)$ \\
\hline$g_{21}^{* * * * *}$ & -0.038 & $(0.112)$ & 0.540 & $(0.000)$ & $g_{12}^{* * * *}$ & 0.004 & $(0.619)$ & -0.324 & $(0.000)$ \\
\hline Log-lik & \multicolumn{2}{|l|}{-18387.88} & \multicolumn{2}{|c|}{-10577.43} & & & & & \\
\hline$Q_{\text {Oil }(10)}$ & \multicolumn{2}{|l|}{4.146} & & & \multicolumn{3}{|l|}{$\operatorname{Arch}(10)_{O i l}$} & \multicolumn{2}{|l|}{2.169} \\
\hline$Q_{O i l(10)}^{2}$ & \multicolumn{2}{|l|}{15.611} & & & $\operatorname{Arch}(10)_{\text {Soya }}$ & & & \multicolumn{2}{|l|}{1.138} \\
\hline$Q_{E t h .(10)}$ & & & \multicolumn{2}{|l|}{13.462} & $\operatorname{Arch}(10)_{\text {Ethanol }}$ & & & \multicolumn{2}{|l|}{0.917} \\
\hline$Q_{E t h .(10)}^{2}$ & & & \multicolumn{2}{|l|}{5.837} & & & & & \\
\hline$Q_{\text {Soya }(10)}$ & \multicolumn{2}{|l|}{5.981} & \multicolumn{2}{|l|}{3.356} & & & & & \\
\hline$Q_{\text {Soya }(10)}^{2}$ & \multicolumn{2}{|l|}{5.799} & \multicolumn{2}{|l|}{2.117} & & & & & \\
\hline
\end{tabular}

Note: See notes in Table 5.

Table 9

Estimated VAR-GARCH(1,1) model, oil-sugar and ethanol-sugar.

\begin{tabular}{|c|c|c|c|c|c|c|c|c|c|}
\hline & \multicolumn{2}{|c|}{ Oil $=>$ Sugar } & \multicolumn{2}{|c|}{ Eth. $=>$ Sugar } & & \multicolumn{2}{|c|}{ Sugar $=>$ Oil } & \multicolumn{2}{|c|}{ Sugar $=>$ Eth. } \\
\hline & Coef. & $p$-Value & Coef. & $p$-Value & & Coef. & $p$-Value & Coef. & $p$-Value \\
\hline \multicolumn{10}{|c|}{ Conditional mean } \\
\hline$\alpha_{1}$ & 0.049 & $(0.297)$ & -0.083 & $(0.024)$ & $\alpha_{2}$ & 0.005 & (0.903) & 0.002 & $(0.958)$ \\
\hline$\beta_{11}$ & -0.057 & $(0.001)$ & 0.084 & $(0.000)$ & $\beta_{22}$ & -0.046 & $(0.076)$ & -0.078 & $(0.000)$ \\
\hline$\beta_{12}$ & 0.203 & $(0.000)$ & 0.001 & $(0.948)$ & $\beta_{21}$ & 0.078 & $(0.035)$ & -0.099 & $(0.000)$ \\
\hline$\beta_{12}^{*}$ & -0.067 & $(0.260)$ & -0.107 & $(0.135)$ & $\beta_{21}^{*}$ & 0.012 & $(0.863)$ & 0.016 & $(0.563)$ \\
\hline$\beta_{12}^{* *}$ & -0.068 & $(0.314)$ & 0.022 & $(0.598)$ & $\beta_{21}^{* *}$ & -0.028 & $(0.542)$ & 0.079 & $(0.005)$ \\
\hline$\beta_{12}^{* * *}$ & -0.004 & $(0.950)$ & 0.098 & $(0.123)$ & $\beta_{21}^{* * *}$ & -0.093 & $(0.126)$ & -0.013 & $(0.717)$ \\
\hline$\beta_{12}^{* * * *}$ & -0.155 & $(0.043)$ & 0.007 & $(0.864)$ & $\beta_{21}^{* * * *}$ & 0.003 & $(0.944)$ & 0.100 & $(0.025)$ \\
\hline$\gamma_{1}$ & 0.063 & $(0.070)$ & -0.008 & $(0.766)$ & $\gamma_{2}$ & 0.046 & $(0.085)$ & 0.059 & $(0.033)$ \\
\hline \multicolumn{10}{|c|}{ Conditional variance } \\
\hline$c_{11}$ & 0.160 & $(0.000)$ & 0.307 & $(0.000)$ & $c_{22}$ & 0.000 & (0.999) & 0.062 & $(0.595)$ \\
\hline$c_{12}$ & 0.194 & $(0.000)$ & 0.092 & $(0.182)$ & & & & & \\
\hline$a_{11}$ & 0.189 & $(0.000)$ & 0.440 & $(0.000)$ & $a_{22}$ & 0.218 & $(0.000)$ & 0.157 & $(0.000)$ \\
\hline$a_{21}$ & -0.075 & $(0.191)$ & 0.021 & $(0.195)$ & $a_{12}$ & 0.058 & $(0.126)$ & -0.010 & $(0.914)$ \\
\hline$a_{21}^{*}$ & 0.028 & $(0.491)$ & -0.228 & $(0.071)$ & $a_{12}^{*}$ & 0.178 & $(0.010)$ & -0.018 & $(0.725)$ \\
\hline$a_{21}^{* *}$ & 0.149 & $(0.022)$ & -0.013 & $(0.911)$ & $a_{12}^{* *}$ & -0.109 & $(0.065)$ & -0.026 & $(0.757)$ \\
\hline$a_{21}^{* * *}$ & -0.032 & $(0.430)$ & 0.265 & $(0.000)$ & $a_{12}^{* * *}$ & -0.183 & $(0.000)$ & -0.048 & $(0.423)$ \\
\hline$a_{21}^{* * * *}$ & 0.020 & $(0.778)$ & -0.030 & $(0.741)$ & $a_{12}^{* * * *}$ & -0.075 & $(0.175)$ & 0.076 & $(0.356)$ \\
\hline$g_{11}$ & -0.981 & $(0.000)$ & 0.892 & $(0.000)$ & $g_{22}$ & 0.974 & $(0.000)$ & 0.157 & $(0.000)$ \\
\hline$g_{21}$ & 0.315 & $(0.000)$ & -0.015 & $(0.176)$ & $g_{12}$ & 0.058 & $(0.126)$ & -0.010 & $(0.914)$ \\
\hline$g_{21}^{*}$ & 0.035 & $(0.607)$ & 0.008 & $(0.770)$ & $g_{12}^{*}$ & 0.178 & $(0.010)$ & -0.018 & $(0.725)$ \\
\hline$g_{21}^{* *}$ & -0.245 & $(0.000)$ & 0.002 & $(0.951)$ & $g_{12}^{* *}$ & -0.109 & $(0.065)$ & -0.026 & $(0.757)$ \\
\hline$g_{21}^{* * *}$ & 0.172 & $(0.000)$ & -0.003 & $(0.892)$ & $g_{12}^{* * *}$ & -0.183 & $(0.000)$ & -0.048 & $(0.423)$ \\
\hline
\end{tabular}


Table 9 (continued)

\begin{tabular}{|c|c|c|c|c|c|c|c|c|c|}
\hline & \multicolumn{2}{|c|}{ Oil $=>$ Sugar } & \multicolumn{2}{|c|}{ Eth. $=>$ Sugar } & & \multicolumn{2}{|c|}{ Sugar $=>$ Oil } & \multicolumn{2}{|c|}{ Sugar $=>$ Eth.} \\
\hline & Coef. & $p$-Value & Coef. & $p$-Value & & Coef. & $p$-Value & Coef. & $p$-Value \\
\hline$g_{21}^{* * * *}$ & -0.501 & $(0.000)$ & 0.002 & $(0.936)$ & $g_{12}^{* * * *}$ & -0.075 & $(0.175)$ & 0.076 & $(0.356)$ \\
\hline Log-lik & -11727.36 & & & -9589.11 & & & & & \\
\hline$Q_{\text {oil }(10)}$ & 4.520 & & & & $\operatorname{Arch}(10)_{O i l}$ & & & 1.127 & \\
\hline$Q_{O i l(10)}^{2}$ & 11.610 & & & & $\operatorname{Arch}(10)_{\text {Sugar }}$ & & & 1.564 & \\
\hline$Q_{E t h .(10)}$ & & 14.077 & & & $\operatorname{Arch}(10)_{\text {Ethanol }}$ & & & 0.625 & \\
\hline$Q_{E t h .(10)}^{2}$ & & 6.710 & & & & & & & \\
\hline$Q_{\text {Sugar }(10)}$ & 9.430 & 8.370 & & & & & & & \\
\hline$Q_{\text {Sugar }(10)}^{2}$ & 9.150 & 10.863 & & & & & & & \\
\hline
\end{tabular}

Note: See notes in Table 5.

Table 10

Estimated VAR-GARCH(1,1) model, oil-wheat and ethanol-wheat.

\begin{tabular}{|c|c|c|c|c|c|c|c|c|c|}
\hline & \multicolumn{2}{|c|}{ Oil $=>$ Wheat } & \multicolumn{2}{|c|}{ Eth. $=>$ Wheat } & & \multicolumn{2}{|c|}{ Wheat $=>$ Oil } & \multicolumn{2}{|c|}{ Wheat $=>$ Eth . } \\
\hline & Coef. & $p$-Value & Coef. & $p$-Value & & Coef. & $p$-Value & Coef. & $p$-value \\
\hline \multicolumn{10}{|c|}{ Conditional mean } \\
\hline$\alpha_{1}$ & 0.013 & $(0.759)$ & 0.001 & $(0.986)$ & $\alpha_{2}$ & -0.012 & $(0.802)$ & -0.021 & $(0.689)$ \\
\hline$\beta_{11}$ & -0.053 & $(0.004)$ & 0.100 & $(0.000)$ & $\beta_{22}$ & -0.037 & $(0.098)$ & -0.038 & $(0.043)$ \\
\hline$\beta_{12}$ & -0.060 & $(0.174)$ & 0.038 & $(0.005)$ & $\beta_{21}$ & -0.009 & $(0.843)$ & -0.016 & $(0.843)$ \\
\hline$\beta_{12}^{*}$ & -0.030 & $(0.660)$ & -0.063 & $(0.542)$ & $\beta_{21}^{*}$ & -0.207 & $(0.017)$ & -0.098 & $(0.073)$ \\
\hline$\beta_{12}^{* *}$ & 0.063 & $(0.304)$ & -0.035 & $(0.239)$ & $\beta_{21}^{* *}$ & 0.131 & $(0.048)$ & 0.017 & $(0.840)$ \\
\hline$\beta_{12}^{* * *}$ & 0.035 & $(0.571)$ & 0.069 & $(0.492)$ & $\beta_{21}^{* * *}$ & -0.067 & $(0.470)$ & -0.016 & $(0.777)$ \\
\hline$\beta_{12}^{* * * *}$ & 0.022 & $(0.718)$ & -0.046 & $(0.160)$ & $\beta_{21}^{* * * *}$ & 0.203 & $(0.020)$ & 0.107 & $(0.211)$ \\
\hline$\gamma_{1}$ & 0.085 & $(0.024)$ & -0.037 & $(0.253)$ & $\gamma_{2}$ & 0.026 & $(0.551)$ & -0.033 & $(0.489)$ \\
\hline \multicolumn{10}{|c|}{ Conditional variance } \\
\hline$c_{11}$ & 0.054 & $(0.266)$ & 0.336 & $(0.000)$ & $c_{22}$ & 0.000 & $(0.999)$ & 0.317 & $(0.000)$ \\
\hline$c_{12}$ & 0.378 & $(0.000)$ & -0.110 & $(0.082)$ & & & & & \\
\hline$a_{11}$ & 0.179 & $(0.000)$ & 0.416 & $(0.000)$ & $a_{22}$ & 0.268 & $(0.000)$ & 0.241 & $(0.000)$ \\
\hline$a_{21}$ & -0.064 & $(0.235)$ & 0.001 & $(0.965)$ & $a_{12}$ & 0.033 & $(0.031)$ & 0.058 & $(0.330)$ \\
\hline$a_{21}^{*}$ & 0.021 & $(0.680)$ & -0.225 & $(0.087)$ & $a_{12}^{*}$ & 0.021 & $(0.493)$ & 0.061 & $(0.381)$ \\
\hline$a_{21}^{* *}$ & 0.061 & $(0.397)$ & 0.105 & $(0.002)$ & $a_{12}^{* *}$ & -0.122 & $(0.000)$ & -0.054 & $(0.408)$ \\
\hline$a_{21}^{* * *}$ & 0.035 & $(0.223)$ & 0.167 & $(0.177)$ & $a_{12}^{* * *}$ & 0.124 & $(0.000)$ & -0.218 & $(0.074)$ \\
\hline$a_{21}^{* * * *}$ & 0.062 & $(0.453)$ & 0.027 & $(0.470)$ & $a_{12}^{* * * *}$ & -0.176 & $(0.000)$ & 0.076 & $(0.618)$ \\
\hline$g_{11}$ & 0.983 & $(0.000)$ & 0.901 & $(0.000)$ & $g_{22}$ & 0.950 & $(0.000)$ & 0.960 & $(0.000)$ \\
\hline$g_{21}$ & -0.014 & $(0.275)$ & 0.023 & $(0.060)$ & $g_{12}$ & 0.033 & $(0.031)$ & -0.099 & $(0.078)$ \\
\hline$g_{21}^{*}$ & -0.028 & $(0.052)$ & 0.071 & $(0.031)$ & $g_{12}^{*}$ & 0.021 & $(0.000)$ & -0.067 & $(0.067)$ \\
\hline$g_{21}^{* *}$ & 0.098 & $(0.000)$ & -0.033 & $(0.020)$ & $g_{12}^{* *}$ & -0.122 & $(0.000)$ & 0.095 & $(0.087)$ \\
\hline$g_{21}^{* * *}$ & -0.091 & $(0.000)$ & -0.078 & $(0.012)$ & $g_{12}^{* * *}$ & 0.124 & $(0.000)$ & 0.164 & $(0.001)$ \\
\hline$g_{21}^{* * * *}$ & 0.110 & $(0.000)$ & 0.000 & $(0.994)$ & $g_{12}^{* * * *}$ & -0.176 & $(0.000)$ & 0.010 & $(0.886)$ \\
\hline Log-lik & \multicolumn{2}{|l|}{-21004.99} & \multicolumn{2}{|l|}{-22147.92} & & & & & \\
\hline$Q_{O i l(10)}$ & 4.831 & & & & $\operatorname{Arch}(10)_{\text {Oil }}$ & & & 0.863 & \\
\hline$Q_{O i l(10)}^{2}$ & 7.334 & & & & $\operatorname{Arch}(10)_{\text {Wheat }}$ & & & 1.646 & \\
\hline$Q_{E t h .(10)}$ & & & 17.063 & & $\operatorname{Arch}(10)_{\text {Ethanol }}$ & & & 0.287 & \\
\hline$Q_{E t h .(10)}^{2}$ & & & 2.514 & & & & & & \\
\hline$Q_{\text {Wheat.(10) }}$ & 6.081 & & 6.426 & & & & & & \\
\hline$Q_{\text {Wheat.(10) }}^{2}$ & 12.230 & & 14.891 & & & & & & \\
\hline
\end{tabular}

Note: See notes in Table 5. 
Table 11

Estimated VAR-GARCH(1,1) model, ethanol-oil.

\begin{tabular}{|c|c|c|c|c|c|}
\hline & \multicolumn{2}{|c|}{ Eth. $=>$ Oil } & & \multicolumn{2}{|c|}{ Oil $=>$ Eth } \\
\hline & Coef. & $p$-Value & & Coef. & $p$-Value \\
\hline \multicolumn{6}{|c|}{ Conditional mean } \\
\hline$\alpha_{1}$ & -0.092 & $(0.009)$ & $\alpha_{2}$ & 0.037 & $(0.473)$ \\
\hline$\beta_{11}$ & 0.091 & $(0.000)$ & $\beta_{22}$ & -0.066 & $(0.000)$ \\
\hline$\beta_{12}$ & 0.003 & $(0.796)$ & $\beta_{21}$ & -0.174 & $(0.010)$ \\
\hline$\beta_{12}^{*}$ & -0.011 & $(0.912)$ & $\beta_{21}^{*}$ & 0.055 & $(0.422)$ \\
\hline$\beta_{12}^{* *}$ & -0.062 & $(0.012)$ & $\beta_{21}^{* *}$ & 0.149 & $(0.025)$ \\
\hline$\beta_{12}^{* * *}$ & 0.044 & $(0.653)$ & $\beta_{21}^{* * *}$ & 0.002 & $(0.986)$ \\
\hline$\beta_{12}^{* * * *}$ & -0.023 & $(0.375)$ & $\beta_{21}^{* * * *}$ & 0.180 & $(0.000)$ \\
\hline$\gamma_{1}$ & -0.004 & $(0.888)$ & $\gamma_{2}$ & 0.041 & $(0.236)$ \\
\hline \multicolumn{6}{|c|}{ Conditional variance } \\
\hline$c_{11}$ & 0.283 & $(0.000)$ & $c_{22}$ & 0.135 & $(0.001)$ \\
\hline$c_{12}$ & -0.014 & $(0.849)$ & & & \\
\hline$a_{11}$ & 0.435 & $(0.000)$ & $a_{22}$ & 0.175 & $(0.000)$ \\
\hline$a_{21}$ & 0.003 & $(0.854)$ & $a_{12}$ & 0.216 & $(0.000)$ \\
\hline$a_{21}^{*}$ & 0.280 & $(0.013)$ & $a_{12}^{*}$ & -0.023 & $(0.627)$ \\
\hline$a_{21}^{* *}$ & -0.068 & $(0.242)$ & $a_{12}^{* *}$ & -0.194 & $(0.003)$ \\
\hline$a_{21}^{* * *}$ & -0.228 & $(0.040)$ & $a_{12}^{* * *}$ & -0.160 & $(0.063)$ \\
\hline$a_{21}^{* * * *}$ & 0.003 & $(0.922)$ & $a_{12}^{* * * *}$ & -0.040 & $(0.622)$ \\
\hline$g_{11}$ & 0.895 & $(0.000)$ & $g_{22}$ & 0.982 & $(0.000)$ \\
\hline$g_{21}$ & 0.008 & $(0.301)$ & $g_{12}$ & -0.105 & $(0.000)$ \\
\hline$g_{21}^{*}$ & -0.044 & (0.299) & $g_{12}^{*}$ & 0.024 & $(0.244)$ \\
\hline$g_{21}^{* *}$ & 0.007 & $(0.649)$ & $g_{12}^{* *}$ & 0.091 & $(0.000)$ \\
\hline$g_{21}^{* * *}$ & 0.040 & $(0.381)$ & $g_{12}^{* * *}$ & 0.026 & $(0.557)$ \\
\hline$g_{21}^{* * * *}$ & -0.011 & $(0.340)$ & $g_{12}^{* * * *}$ & 0.059 & $(0.107)$ \\
\hline Log-lik & -9982.98 & & & & \\
\hline$Q_{o i l(10)}$ & 6.901 & & $\operatorname{Arch}(10)_{O i l}$ & & 1.781 \\
\hline$Q_{O i l(10)}^{2}$ & 15.743 & & $\operatorname{Arch}(10)_{\text {Ethanol }}$ & & 0.721 \\
\hline$Q_{E t h .(10)}$ & 16.092 & & & & \\
\hline$Q_{\text {Eth.(10) }}^{2}$ & 6.468 & & & & \\
\hline
\end{tabular}

Note: See notes in Table 5. 

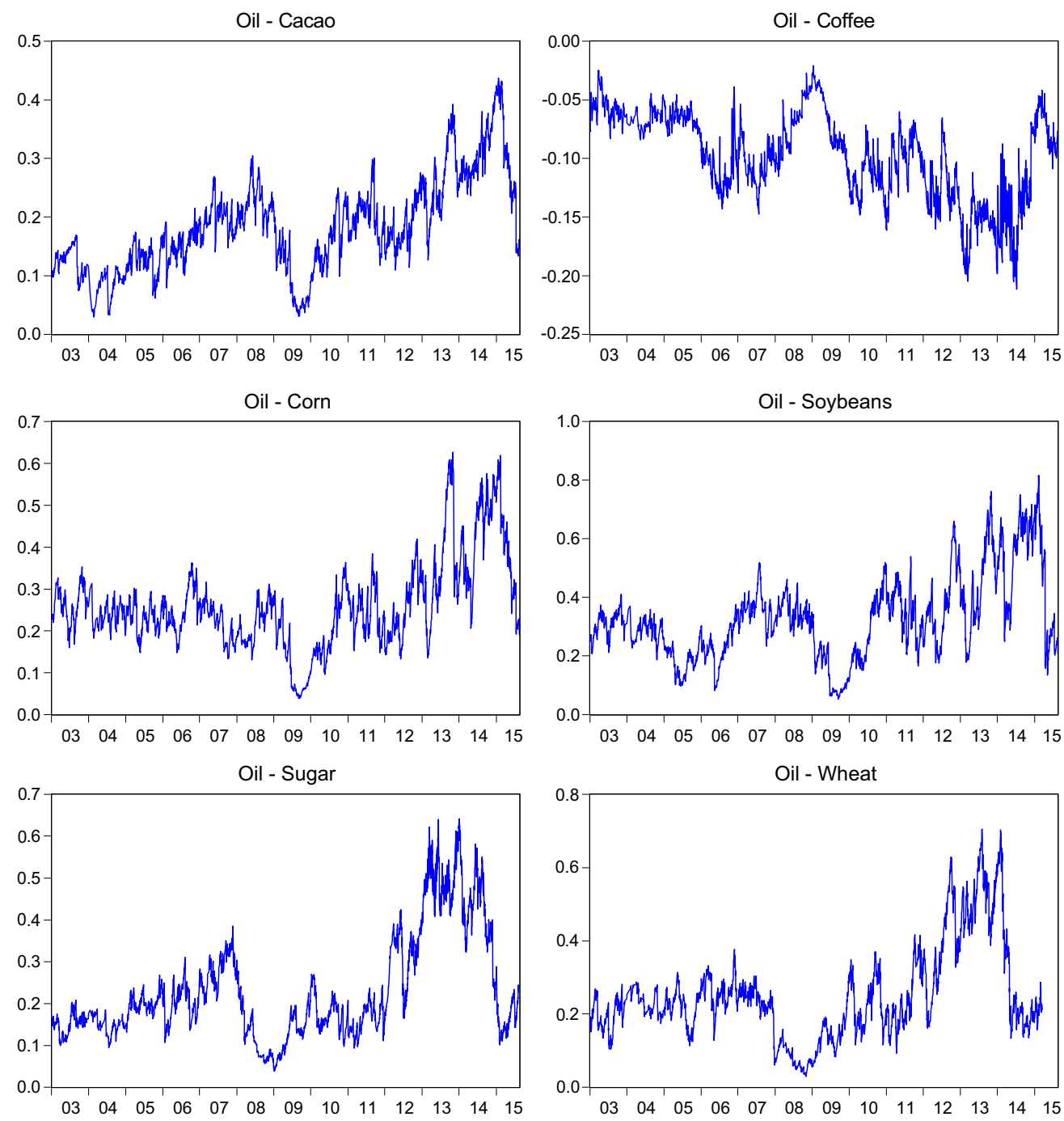

Fig. 3. Conditional correlations. 

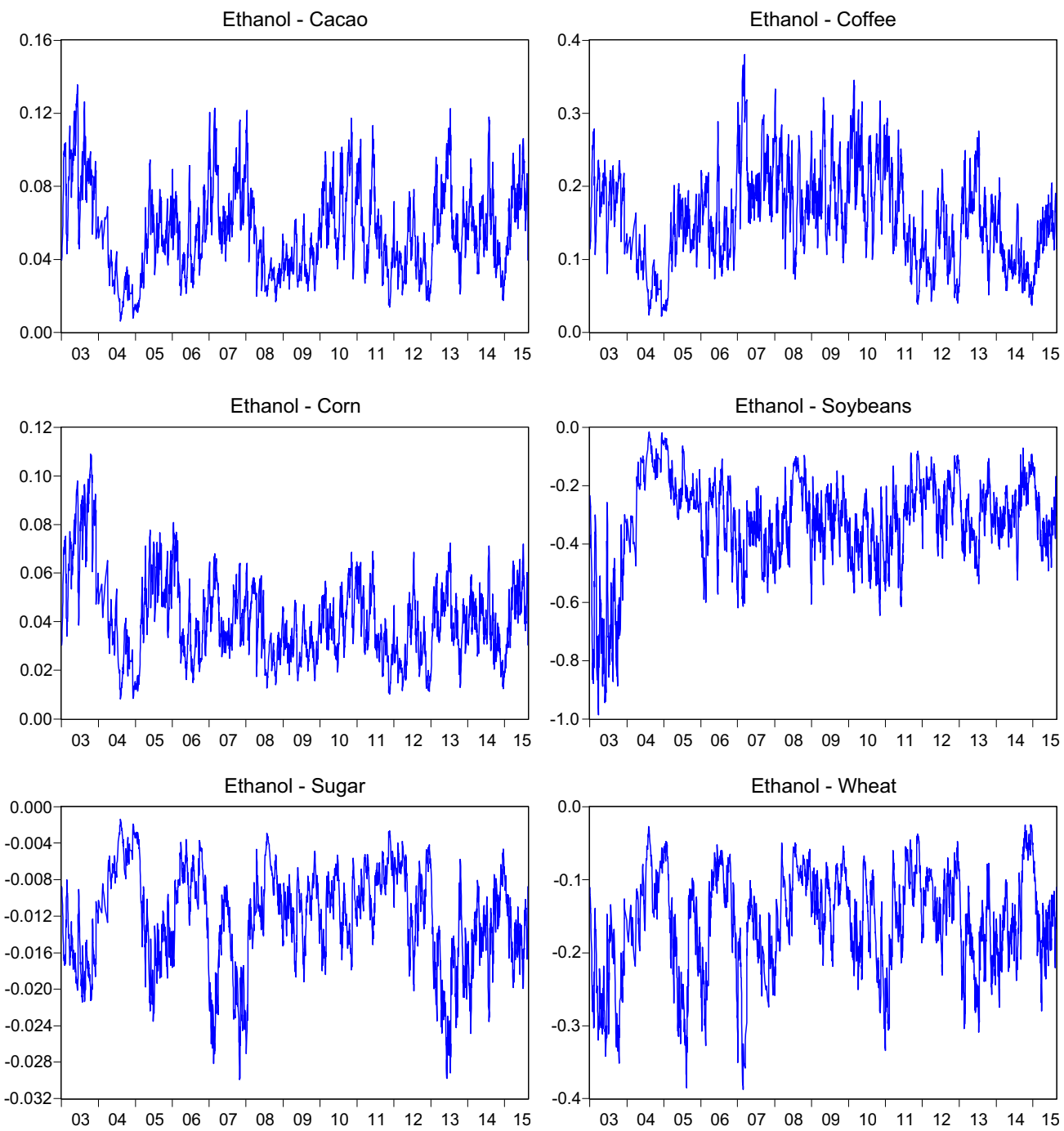

Fig. 4. Conditional correlations.

\section{Acknowledgements}

We would like to thank participants at the Qatar Foundation Annual Research Conference, and two anonymous referees for helpful comments and suggestions.

\section{References}

Abbott, P., Hurt. C., Tyner, W., 2009. What's Driving Food Prices? Farm Foundation, No. 48495.

Andersen, T., Bollerslev, T., Diebold, F.X., Labys, P., 2003. Modeling and forecasting realized volatility. Econometrica 71 (2), $579-625$.

Avalos, F., 2014. Do oil prices drive food prices? The tale of a structural break. J. Int. Money Financ. 42, $253-271$.

Baquedano, F., Liefert, W., 2014. Market integration and price transmission in consumer markets of developing countries. Food Policy 44, $103-114$.

Barnard, J., 1983. Gasohol/ethanol: a review of national and regional policy and feasibility issues. Reg. Sci. Perspect. 13 (2), 3-14.

Campbell, J.Y., 1999. Asset prices, consumption and the business cycle. In: Handbook of Macroeconomics, vol. 1, pp. 1231-1303.

Caporin, M., McAleer, M., 2012. Do we really need both BEKK and DCC? A tale of two multivariate GARCH models. J. Econ. Surv. 26, 736-751.

Chen, P., Chien-Chiang, L., Zeng, J., 2014. The relationship between spot and futures oil prices: do structural breaks matter? Energy Econ. 43 , 206-217.

de Gorter, H., Drabik, D., Just, D.R., 2013. How biofuels policies affect the level of grains and oilseed prices: theory, models and evidence. Glob. Food Secur. 2 (2), $82-88$.

De Hoyos, R., Medvedev, D., 2011. Poverty effects of higher food prices: a global perspective. Rev. Dev. Econ. 15.3, 387-402.

Du, X., Yu, C., Hayes, D., 2011. Speculation and volatility spillover in the crude oil and agricultural commodity markets: a Bayesian analysis. Energy Econ. 33 (3), 497-503.

Engle, R.F., Kroner, K.F., 1995. Multivariate simultaneous generalized ARCH. Econom. Theory 11 (1), $122-150$. 
Fan, Y., Xu, J., 2011. What has driven oil prices since 2000? A structural change perspective. Energy Econ. 33 (6), $1082-1094$.

Gardebroek, C., Hernandez, M., 2013. Do energy prices stimulate food price volatility? Examining volatility transmission between US oil, ethanol and corn markets. Energy Econ. 40, 119-129.

Han, L., Zhou, Y., Yin, L., 2015. Exogenous impacts on the links between energy and agricultural commodity markets. Energy Econ. 49, 350-358.

Headey, D., 2011. Rethinking the global food crisis: the role of trade shocks. Food Policy 36 (2), 136-146.

Hertel, T.W., Beckman, J., 2011. Commodity price volatility in the biofuel era: an examination of the linkage between energy and agricultural markets. In: The Intended and Unintended Effects of US Agricultural and Biotechnology Policies. University of Chicago Press, pp. 189-221.

Hochman, G., Rajagopal, D., Timilsina, G., Zilberman, D., 2014. Quantifying the causes of the global food commodity price crisis. Biomass Bioenergy 68, 106-114.

Jebabli, I., Arouri, M., Teulon, F., 2014. On the effects of world stock market and oil price shocks on food prices: an empirical investigation based on TVPVAR models with stochastic volatility. Energy Econ. 45, 66-98.

Mensi, W., Hammoudeh, S., Nguyen, D., Yoon, S., 2014. Dynamic spillovers among major energy and cereal commodity prices. Energy Econ. 43, 225-243.

McPhail, L.L., Babcock, B.A., 2012. Impact of US biofuel policy on US corn and gasoline price variability. Energy 37 (1), $505-513$.

Nazlioglu, S., Erdem, C., Soytas, U., 2013. Volatility spillover between oil and agricultural commodity markets. Energy Econ. 36, $658-665$.

Olson, E., Vivian, A.J., Wohar, M.E., 2014. The relationship between energy and equity markets: evidence from volatility impulse response functions. Energy Econ. 43, 297-305.

Qiu, C., Colson, G., Escalante, C., Wetzstein, M., 2012. Considering macroeconomic indicators in the food before fuel nexus. Energy Econ. 34, $2021-2028$.

Serra, T., Zilberman, D., Gil, J.M., Goodwin, B.K., 2011. Nonlinearities in the US corn-ethanol-oil-gasoline price system. Agric. Econ. 42 (1), 35-45.

Serra, T., 2011. Volatility spillovers between food and energy markets: a semiparametric approach. Energy Econ. 33, 1155-1164.

Serra, T., Zilberman, D., 2013. Biofuel-related price transmission literature: a review. Energy Econ. 37, $141-151$.

Timilsina, G.R., Mevel, S., Shrestha, A., 2011. Oil price, biofuels and food supply. Energy Policy 39 (12), 8098-8105.

Trujillo-Barrera, A., Mallory, M., Garcia, P., 2012. Volatility spillovers in US crude oil, ethanol, and corn futures markets. J. Agric. Resour. Econ. 37 (2), 247.

Wang, X., Zhang, C., 2014. The impacts of global oil price shocks on China's fundamental industries. Energy Policy 68, 394-402.

Wright, B., 2011. Addressing the Biofuels Problem: Food Security Options for Agricultural Feedstocks. In: Prakash, A. (Ed.), Safeguarding Food Security in Volatile Global Markets. FAO, Rome, pp. 479-490.

Wu, F., Guan, Z., Myers, R., 2011. Volatility spillover effects and cross hedging in corn and crude oil futures. J. Futures Mark. 31 (11), $1052-1075$.

Zhang, Z., Lohr, L., Escalante, C., Wetzstein, M., 2009. Ethanol, corn, and soybean price relations in a volatile vehicle-fuels market. Energies 2 (2), 320-339. 